\title{
Investigating vegetation-climate feedbacks during the early Eocene
}

\author{
C. A. Loptson ${ }^{1}$, D. J. Lunt ${ }^{1}$, and J. E. Francis ${ }^{2}$ \\ ${ }^{1}$ School of Geographical Sciences, University Road, Bristol, BS8 1SS, UK \\ ${ }^{2}$ British Antarctic Survey, Cambridge, CB3 OET, UK \\ Correspondence to: C. A. Loptson (c.loptson@bristol.ac.uk)
}

Received: 26 July 2013 - Published in Clim. Past Discuss.: 14 August 2013

Revised: 19 December 2013 - Accepted: 27 January 2014 - Published: 7 March 2014

\begin{abstract}
Evidence suggests that the early Eocene was a time of extreme global warmth. However, there are discrepancies between the results of many previous modelling studies and the proxy data at high latitudes, with models struggling to simulate the shallow temperature gradients of this time period to the same extent as the proxies indicate. Vegetation-climate feedbacks play an important role in the present day, but are often neglected in these palaeoclimate modelling studies, and this may be a contributing factor to resolving the model-data discrepancy.

Here we investigate these vegetation-climate feedbacks by carrying out simulations of the early Eocene climate at $2 \times$ and $4 \times$ pre-industrial atmospheric $\mathrm{CO}_{2}$ with fixed vegetation (homogeneous shrubs everywhere) and dynamic vegetation.

The results show that the simulations with dynamic vegetation are warmer in the global annual mean than the simulations with fixed shrubs by $0.9^{\circ} \mathrm{C}$ at $2 \times$ and $1.8^{\circ} \mathrm{C}$ at $4 \times$. Consequently, the warming when $\mathrm{CO}_{2}$ is doubled from $2 \times$ to $4 \times$ is $1^{\circ} \mathrm{C}$ higher (in the global annual mean) with dynamic vegetation than with fixed shrubs. This corresponds to an increase in climate sensitivity of $26 \%$. This difference in warming is enhanced at high latitudes, with temperatures increasing by over $50 \%$ in some regions of Antarctica. In the Arctic, ice-albedo feedbacks are responsible for the majority of this warming. On a global scale, energy balance analysis shows that the enhanced warming with dynamic vegetation is mainly associated with an increase in atmospheric water vapour but changes in clouds also contribute to the temperature increase. It is likely that changes in surface albedo due to changes in vegetation cover resulted in an initial warming which triggered these water vapour feedbacks.

In conclusion, dynamic vegetation goes some way to resolving the discrepancy, but our modelled temperatures
\end{abstract}

cannot reach the same warmth as the data suggest in the Arctic. This suggests that there are additional mechanisms, not included in this modelling framework, behind the polar warmth or that the proxies have been misinterpreted.

\section{Introduction}

The warmest climates of the past 65 million years occurred during the early Eocene (56-48 Ma) (Sloan and Morrill, 1998; Huber and Caballero, 2011), with benthic foraminifera indicating deep water temperatures of around $10^{\circ} \mathrm{C}$ (Zachos et al., 2001) compared to between 2 and $3{ }^{\circ} \mathrm{C}$ in the present day (Martin et al., 2002). It is probable that there was little or no permanent ice, even at polar regions (Zachos et al., 2001, 2006). Atmospheric carbon dioxide levels were higher during the early Eocene compared to today, with proxy-derived estimates ranging from 300 to over $4000 \mathrm{ppm}$ (Beerling and Royer, 2011; Lowenstein and Demicco, 2006; Pagani et al., 2009; Sluijs et al., 2006; Pearson et al., 2007).

The latitudinal temperature gradients were much shallower than the present day (Bijl et al., 2009). Equatorial regions were only slightly warmer, with sea surface temperatures (SSTs) of $30-35^{\circ} \mathrm{C}$ compared to the present-day values of $25-30^{\circ} \mathrm{C}$ (Pearson et al., 2007), but high latitudes were much warmer with SST estimates of 17 or $18^{\circ} \mathrm{C}$ in the Arctic during the early Eocene (Sluijs et al., 2008). Until recently, models have had great difficulty in replicating this feature of the climate, instead producing temperatures that are cooler than indicated by the data in the high latitudes or temperatures that are higher than indicated by the proxies in the tropics (e.g. Heinemann et al., 2009; Winguth et al., 2010; Shellito et al., 2009; Roberts et al., 2009; Shellito et al., 2003). This is due to the fact that the specific mechanisms 
that cause this shallow temperature gradient are unknown or not fully understood so cannot be accounted for (Winguth et al., 2010; Beerling et al., 2011; Sloan and Morrill, 1998).

To date, there have been several attempts to model the early Eocene climate. So far no models have been completely consistent with the evidence and data available. Some models are capable of reproducing some characteristics of the early Eocene climate, but do not fully explain the mechanisms behind it.

Good agreement between proxy data and model results was achieved by Huber and Caballero (2011) except at some high-latitude and all deep-sea locations. However, the $\mathrm{CO}_{2}$ level prescribed in the model $(4480 \mathrm{ppm})$ is at the upper limit of proxy predictions (Huber, 2008; Jaramillo et al., 2010; Pearson et al., 2007). Increased atmospheric $\mathrm{CO}_{2}$ levels alone are not sufficient to completely explain the early Eocene latitudinal temperature gradient (Sloan et al., 1995). There have been several suggested mechanisms for the relatively warm high latitudes, including enhanced poleward heat transport (Sloan et al., 1995), polar stratospheric clouds (Sloan and Pollard, 1998), aerosols (Kump and Pollard, 2008), different greenhouse gases (GHGs) (Beerling et al., 2011), and vegetation feedbacks (OttoBliesner and Upchurch, 1997). There is increasing evidence that cloud feedbacks - including high-latitude cloud cover (Sagoo et al., 2013), reduction in low-level clouds (Poulsen and Zhou, 2013), and cloud condensation nuclei (Kiehl and Shields, 2013) - were crucial mechanisms for the highlatitude warmth during the early Eocene.

However, previous modelling studies for the early Eocene, such as those included in the Eocene Model Intercomparison Project (Lunt et al., 2012), have generally neglected vegetation feedbacks. These experiments used a fixed vegetation distribution of either one vegetation type covering all land (e.g. homogeneous shrubland as in the Hadley Centre Model, HadCM3L, simulations) or a "best-guess" distribution such as that of Sewall et al. (2000). Vegetation can have a significant effect on the climate (Bonan, 2008). For example, boreal forests have a larger biogeophysical effect than other biomes on annual mean global temperature due to albedo effects when snow is present; the trees, which have a low albedo, mask the high albedo of snow during the winter. Evapotranspiration affects the climate through cloud and precipitation feedbacks. The overall impact on climate (i.e. whether the net feedback is positive or negative) depends on the type of vegetation present. For example, tropical forests are a negative climate forcing because the cooling effect of evapotranspiration is greater than the warming due to the low forest albedo, whereas boreal forests amplify warming because the albedo contribution dominates (Bonan, 2008).

In an attempt to discover which plant functional types (PFTs) that exist today could have existed during the Eocene, Shellito and Sloan (2006a) employed a dynamic global vegetation model (DGVM) integrated with the NCAR LSM (National Center for Atmospheric Research Land Surface
Model) (Bonan et al., 2003) and found that grasses were the dominant PFT, which is not consistent with fossil evidence (e.g. Utescher and Mosbrugger, 2007). Shellito and Sloan (2006b) carried out further sensitivity studies using the same model as Shellito and Sloan (2006a), and found that soil texture had a large impact on the abundance of PFTs, and that needleleaf and tropical trees were most sensitive to increasing atmospheric $\mathrm{CO}_{2}$ concentrations. These sensitivity studies underline some of the uncertainties associated with DGVMs and show how even a small change in some of the boundary conditions can have a notable effect on the modelled biosphere.

Simulations with fully coupled climate-vegetation models have been carried out for the Holocene (e.g. Notaro et al., 2008; Wang et al., 2008; Liu et al., 2007) and also for past deep-time periods. For example, Zhou et al. (2012) investigated the effects of incorporating dynamic vegetation into Cretaceous simulations and found that the simulations with dynamic vegetation were $0.9^{\circ} \mathrm{C}$ warmer with levels of precipitation $0.11 \mathrm{~mm} \mathrm{day}^{-1}$ higher (relative to bare ground). Therefore, it is important that an accurate representation of vegetation is included in a GCM (general circulation model).

There can be a large difference in vegetation between early and mid-Eocene at high latitudes. Contreras et al. (2013) describe how the vegetation type changes from paratropical to cool temperate type vegetation between the early and middle Eocene. This change in vegetation means that the dating of Eocene fossil flora and pollen needs to be robust when carrying out comparisons between models and data.

Due to all of the feedbacks between vegetation and the climate, it is very important to include a dynamic vegetation component to climate model simulations and that this representation of the vegetation within the model is sensible and realistic, i.e. that the distribution and type of vegetation present in the model shows good agreement with available fossil evidence.

This study addresses four main questions: (1) is the modelled vegetation distribution consistent with available data? (2) What is the effect of vegetation on early Eocene climate? (3) Does incorporating dynamic vegetation reduce the temperature discrepancy between models and data for this time period? (4) What are the reasons behind the changes in temperature when $\mathrm{CO}_{2}$ is doubled and when dynamic vegetation is coupled to HadCM3L?

First, the predicted vegetation distributions are presented. We then investigate the effects of dynamic vegetation on climate by comparing simulations with fixed, prescribed vegetation to simulations that are fully coupled to a dynamic vegetation model. The results of all simulations are then compared to terrestrial and marine proxy data in order to assess the effectiveness of dynamic vegetation in reducing the model-data discrepancy. Energy balance analysis is carried out to diagnose the mechanisms that contribute to the temperature differences between simulations. 
Table 1. Plant functional type parameters in TRIFFID. Temperatures are all in ${ }^{\circ} \mathrm{C}$; LAI is leaf area index.

\begin{tabular}{lrrrrr}
\hline & Broadleaf & Needleleaf & $\mathrm{C}_{3}$ & $\mathrm{C}_{4}$ & Shrub \\
\hline Maximum projected LAI & 10 & 10 & 4 & 4 & 6 \\
Minimum projected LAI & 4 & 4 & 1 & 1 & 1 \\
Lower temperature for photosynthesis & 0 & -5 & 0 & 13 & 0 \\
Upper temperature for photosynthesis & 36 & 31 & 36 & 45 & 36 \\
\hline
\end{tabular}

\section{Methods}

The GCM used in this study is the UK Met Office general circulation model HadCM3L (version 4.5), which has already been used in several palaeoclimate studies of the early Eocene (Tindall et al., 2010; Lunt et al., 2012, 2010a, b). In this study the land surface scheme MOSES 2.1 was used, whereas MOSES 2.2 was used in the previous studies (see Cox et al., 1998, 1999 for a description of MOSES 2). This is because MOSES 2.1 is required for coupling the GCM to the dynamic vegetation model, as it has a better representation of modern vegetation in pre-industrial (PI) simulations. HadCM3L is a coupled atmosphere-ocean model with a resolution of $3.75^{\circ}$ in longitude and $2.5^{\circ}$ in latitude in both the atmosphere and ocean. The GCM has 19 vertical levels in the atmosphere and 20 in the ocean.

The palaeogeography used was created using similar methods to that of Markwick and Valdes (2004). The Arctic is closed in this palaeogeography (i.e. no flow is allowed into or out of the Arctic sea). The regions of maximum orographic height are on the west coast of North America $(\sim 3300 \mathrm{~m})$ and in the centre of Antarctica $(\sim 2000 \mathrm{~m})$.

The dynamic global vegetation model used was TRIFFID (Top-down Representation of Interactive Foliage and Flora Including Dynamics) (Cox, 2001). Through a carbon balance model, which takes into account photosynthesis and respiration, TRIFFID models the percentage of the model grid box occupied by each PFT. The five PFTs simulated by TRIFFID are broadleaf tree, needleleaf tree, $\mathrm{C}_{3}$ grass, $\mathrm{C}_{4}$ grass and shrub. The growth of each PFT in each grid box is dependent on a range of variables including available carbon, moisture, atmospheric $\mathrm{CO}_{2}$ and temperature. Each PFT has its own range of temperatures in which it is able to photosynthesise (see Table 1 for these upper and lower temperature limits) and different albedos (the maximum canopy albedo is 0.1 for trees and 0.2 for grasses and shrubs).

The amount of soil carbon available to the vegetation is increased through litterfall (comprised of leaf, root and stem carbon), and microbial respiration returns soil carbon to the atmosphere at a rate determined by soil moisture and temperature. TRIFFID updates the vegetation and soil carbon every 10 days based on these carbon fluxes (calculated by the land surface model MOSES 2.1) and competition between functional types (trees are at the top of the dominance hierarchy followed by shrubs and then grasses). This information is then fed back to MOSES 2.1. This method verifies that the surface hydrological states experienced by the atmosphere and vegetation are consistent (Cox, 2001).

There is no strong evidence for the existence (or widespread growth) of $\mathrm{C}_{4}$ grasses during the early Eocene (Christin et al., 2011; Edwards et al., 2010; Vicentini et al., 2008). Shellito and Sloan (2006b) eliminated $C_{4}$ grasses from their DGVM and found that it had no effect on the abundance of other PFTs but may have an influence the carbon and hydrological cycles. Instead of $\mathrm{C}_{4}$ grasses, it is likely that ferns would have grown (Donnadieu et al., 2009). In these experiments, $\mathrm{C}_{3}$ and $\mathrm{C}_{4}$ grasses have been combined into a single PFT ("grasses") to represent general non-forest ground cover.

In order to investigate the effects of increased atmospheric $\mathrm{CO}_{2}$ concentrations on the climate alone, two Eocene simulations were carried out with prescribed, fixed vegetation (homogeneous shrubs) covering all areas of land. One simulation was run with $2 \times \mathrm{PI}$ atmospheric $\mathrm{CO}_{2}(560 \mathrm{ppm})$ and the other with $4 \times \mathrm{PI} \mathrm{CO}_{2}$ levels $(1120 \mathrm{ppm})$. These will be referred to as $2 \times$ SHRUB and $4 \times$ SHRUB respectively. These $\mathrm{CO}_{2}$ concentrations were chosen because they span part of the estimated range of atmospheric $\mathrm{CO}_{2}$ during the early Eocene. All other greenhouse gases $\left(\mathrm{CH}_{4}, \mathrm{~N}_{2} \mathrm{O}, \mathrm{O}_{3}\right)$ were set to pre-industrial values. This is due to the absence of proxies for these gases, and also because the uncertainty in radiative forcing is dominated by the uncertainty in $\mathrm{CO}_{2}$ (Tindall et al., 2010).

We are modelling a multi-million-year-long interval (in which many orbital configurations would have occurred) and our aim is to simulate the overall long-term warmth of the early Eocene. Uncertainty in orbital forcing has a relatively small effect on global mean values (Sagoo et al., 2013); therefore we have chosen a modern-day orbit. The solar luminosity was set to a value of $1359.5 \mathrm{Wm}^{-2}$ (a reduction of $0.4 \%$ compared to the present day) in line with Gough (1981).

These simulations with fixed vegetation are a continuation of a set of simulations already in a quasi-steady state, integrated for more than $3400 \mathrm{yr}$ (Lunt et al., 2010a). Continuations of the $2 \times$ SHRUB and $4 \times$ SHRUB were then run, but with HadCM3L coupled to TRIFFID, until the climate system equilibrated $(1000 \mathrm{yr})$. This was done for both $\mathrm{CO}_{2}$ levels, and these simulations will be referred to as $2 \times \mathrm{DYN}$ and $4 \times$ DYN. 
Broadleaf Trees

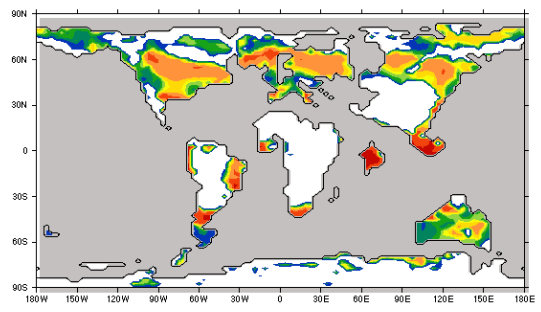

Needleleaf Trees

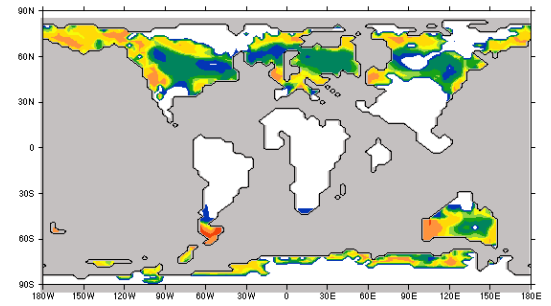

Shrubs

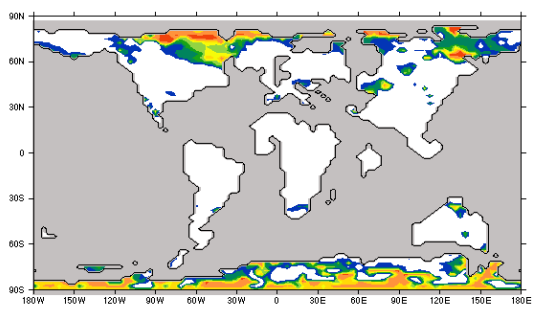

Grasses

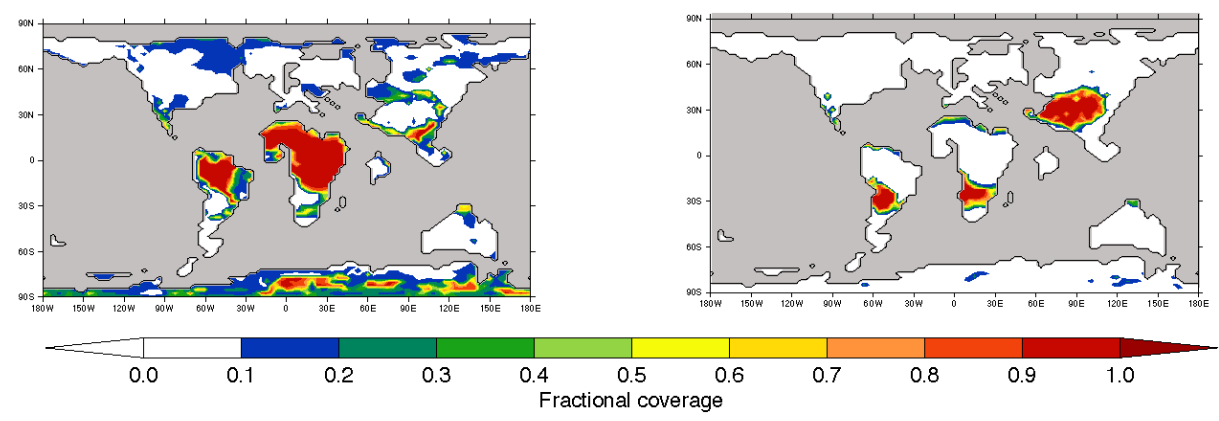

Fig. 1. Global early Eocene vegetation distributions for $2 \times \mathrm{DYN}$ as predicted by TRIFFID.

Changes in climate between $2 \times \mathrm{DYN}$ and $4 \times \mathrm{DYN}$ will inevitably be due to a combination of factors, including increased $\mathrm{CO}_{2}$ and differing vegetation distributions. In order to separate these effects, a further simulation was carried out where the vegetation was prescribed to be the same as the $2 \times$ DYN simulation, but the model was run with $4 \times$ PI $\mathrm{CO}_{2}$. It was run for 550 model years. This simulation will be called $4 \times$ FIXED. All experimental setups are summarised in Table 2.

\section{Results}

\subsection{Predicted vegetation}

Figures 1 and 2 show the global vegetation distributions predicted by TRIFFID for $2 \times$ DYN and $4 \times$ DYN respectively. It can be seen that broadleaf and needleleaf trees move poleward when atmospheric $\mathrm{CO}_{2}$ is doubled from $2 \times$ to $4 \times \mathrm{PI}$ $\mathrm{CO}_{2}$. In contrast, shrubs move towards the Equator. The extent of bare soil increases at low latitudes and grasses disappear almost entirely from Antarctica.

In both the Arctic and Antarctic, $4 \times$ DYN shows broadleaf trees being the dominant PFT where shrubs and grasses had dominated in $2 \times$ DYN. Grasses generally dominate in the tropics in both simulations, but in $4 \times$ DYN the area dominated by grasses increases to cover more of the equatorial regions. This is most noticeable in southeast Asia and South America.
Table 2. Summary of all Eocene model simulations.

\begin{tabular}{lcl}
\hline Experiment name & $\mathrm{CO}_{2}$ level & Vegetation \\
\hline $2 \times$ SHRUB & 2 & Fixed (homogeneous shrubland) \\
$4 \times$ SHRUB & 4 & Fixed (homogeneous shrubland) \\
$2 \times$ DYN & 2 & Dynamic (predicted by TRIFFID) \\
$4 \times$ DYN & 4 & Dynamic (predicted by TRIFFID) \\
$4 \times$ FIXED & 4 & Fixed (vegetation distribution of $2 \times$ DYN) \\
\hline
\end{tabular}

Evidence of plants from the early Eocene has been discovered from various locations worldwide and allows a comparison to be carried out between the modelled vegetation distribution and identified plant fossils from the literature. Fossil evidence suggests that vegetation on the Antarctic Peninsula was mixed broadleaf and coniferous deciduous forest (Francis and Poole, 2002; Cantrill et al., 2011), and on the Antarctic Wilkes Land margin there is evidence of paratropical forest in the early Eocene (Contreras et al., 2013). This is more consistent with the $4 \times$ DYN simulation than the $2 \times$ DYN simulation. Similarly, there is evidence that forests covered high northern latitudes as well (Eberle and Greenwood, 2012; Harrington et al., 2012), which is also most consistent with the $4 \times$ DYN simulation. The location and type of this fossil data are plotted in Fig. 3. However, the predicted vegetation for the tropics is not particularly consistent with fossil evidence. There is evidence for paratropical or tropical forests (Willis and McElwain, 2002, and references therein) across the majority of Africa and tropical regions of Asia and South America. However, TRIFFID predicts bare soil and grasses in both $2 \times$ DYN and $4 \times$ DYN 
Broadleaf Trees

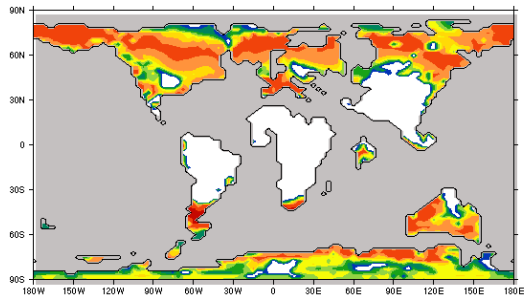

Needleleaf Trees

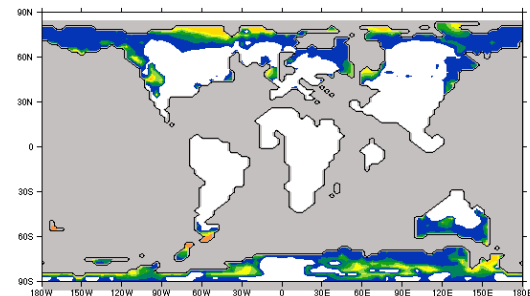

Shrubs

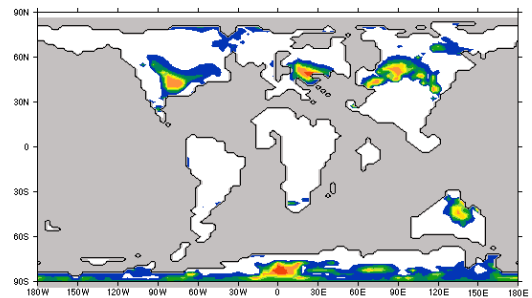

Grasses

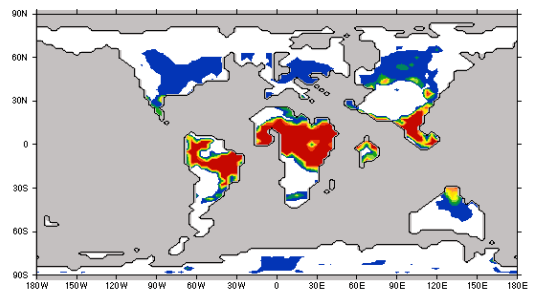

Bare Soil

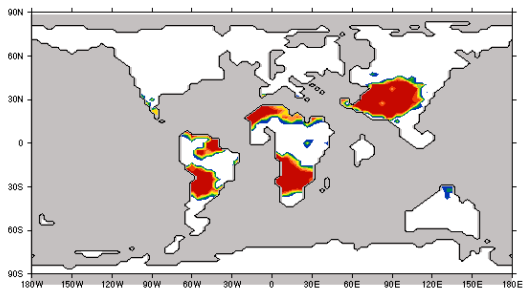

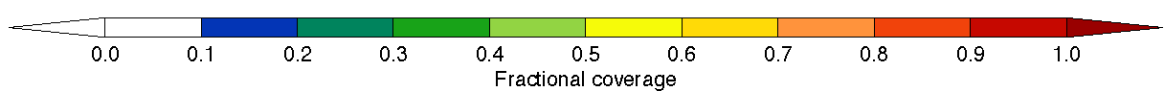

Fig. 2. Global early Eocene vegetation distributions for $4 \times \mathrm{DYN}$ as predicted by TRIFFID.

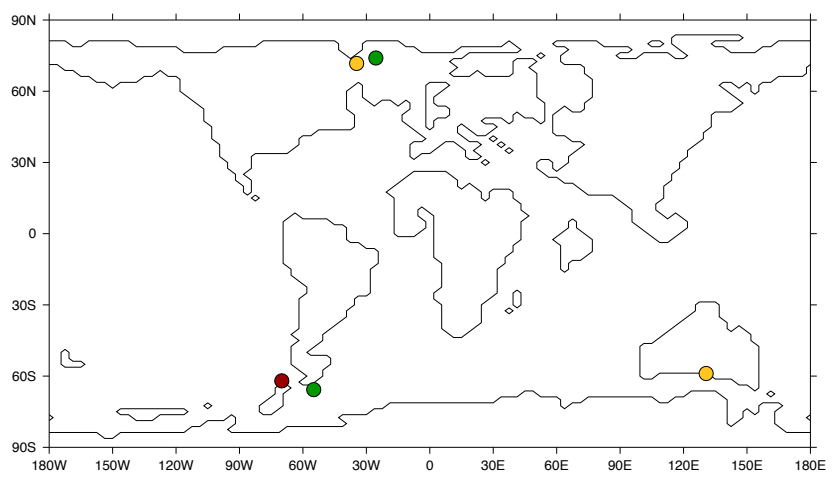

Fig. 3. Locations of some of the fossil evidence from the early Eocene. The red circle represents the location of fossil wood, yellow represents pollen and green represents fossil leaves. Data from Contreras et al. (2013), Francis and Poole (2002), Harrington et al. (2012), Cantrill et al. (2011) and Eberle and Greenwood (2012).

for these regions. The lack of trees over these regions is a feature seen in other studies using HadCM3L and TRIFFID to model past warm climates (e.g. Hunter et al., 2013). Hunter et al. (2013) state that this is due to a dry bias within the model, and forests cannot grow due to water stress.

\subsection{Influence of dynamic vegetation on climate}

\subsubsection{Sea surface temperatures}

Latitudinal SST gradients for simulations at $2 \times$ and $4 \times$ PI $\mathrm{CO}_{2}$ are shown in Fig. 4. It can be seen that at low to mid-latitudes most model results are within the error bars of the SST proxy data. The root mean square error (RMSE), based on the SST data, is $12.8^{\circ} \mathrm{C}$ for $2 \times \mathrm{SHRUB}$, $11.4{ }^{\circ} \mathrm{C}$ for $4 \times \mathrm{SHRUB}, 12.7^{\circ} \mathrm{C}$ for $2 \times \mathrm{DYN}$ and $10.6^{\circ} \mathrm{C}$ for $4 \times \mathrm{DYN}$. This shows that for both $\mathrm{CO}_{2}$ levels, adding dynamic vegetation reduces the model-data discrepancy and that the mean SSTs are generally most consistent with $4 \times$ DYN.

There are potential problems with the data, as proxies are not fully understood and the interpretations may be subject to bias. For example, foraminifera may have undergone diagenetic alteration after deposition, which affects their isotopic composition, and therefore has an impact on inferred temperatures (Pearson et al., 2007). There is uncertainty in the isotopic composition of seawater, as it is likely that this was different in the past (Zhou et al., 2008). It is thought that some proxies may have a bias towards summer temperatures, e.g. the MBT-CBT proxy (Eberle et al., 2010). In addition, many of the species of foraminifera used to infer palaeoclimate are extinct, so it is impossible to know whether the values recorded by them are equilibrium values (Roberts et al., 2009). One of the most recently developed palaeothermometers uses organic compounds (archaeal-derived isoprenoid glycerol dibiphytanyl glycerol tetraethers, or GDGTs) to measure SSTs. There are multiple calibrations for this proxy, and determining the most appropriate calibration can be difficult. Currently there are three different calibrations based on different ratios of GDGTs: $\operatorname{TEX}_{86}^{L}, \mathrm{TEX}_{86}^{H}$ (Kim et al., 2010) and " $1 / \mathrm{TEX}_{86}$ ", a non-linear calibration (Liu et al., 2009), revised by Kim et al. (2010). This proxy is not fully 


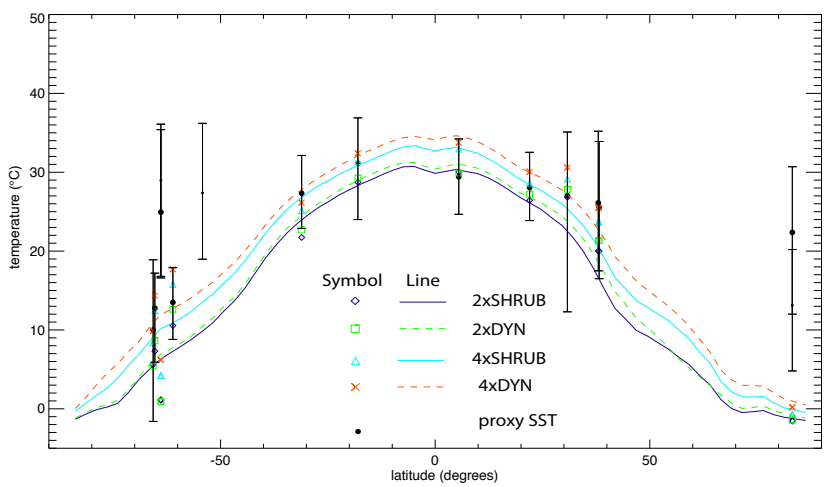

Fig. 4. Zonal mean annual SSTs for $2 \times$ SHRUB (dark-blue diamonds), $2 \times$ DYN (green squares), $4 \times$ SHRUB (light-blue triangles) and $4 \times$ DYN (orange crosses). The black dots show the terrestrial temperatures indicated by proxy data with error bars (the smaller black dots indicate early Eocene climatic optimum temperatures). The coloured shapes show the temperature at the same latitude and longitude as the location of the data as predicted by each model. The lines show the modelled latitudinal temperature gradients for each simulation. Data set from Lunt et al. (2012).

understood, and as a result it is uncertain which calibration is most suitable for each site in the early Eocene (Lunt et al., 2012; Hollis et al., 2012).

These uncertainties in the data, along with the paucity and poor coverage of data means that this calculated root mean square value may not be representative of how well the model can reproduce the early Eocene climate. It can only be a broad indicator of how consistent the model is with the available data.

At high latitudes in the Northern Hemisphere the models predict temperatures over $20^{\circ} \mathrm{C}$ cooler than proxy data. However, the uncertainty of this data point is rather large, spanning a range from 31 to $5^{\circ} \mathrm{C}$. Taking this into account, there is only a $5^{\circ} \mathrm{C}$ discrepancy between the $4 \times$ DYN results and data here. The $4 \times$ SHRUB simulation had a discrepancy of $6{ }^{\circ} \mathrm{C}$ at this same grid point. This is the only data point for comparison in this region and more data would be required to reliably test the performance of the model in the Arctic.

\subsubsection{Terrestrial temperatures}

Figure 5 shows the zonal mean temperatures for each simulation and the terrestrial proxy data. Changing vegetation distribution from SHRUB to DYN has the effect of increasing Northern Hemisphere high-latitude temperatures by approximately $3^{\circ} \mathrm{C}$ at $2 \times \mathrm{CO}_{2}$ and $4{ }^{\circ} \mathrm{C}$ at $4 \times \mathrm{CO}_{2}$. This is due, at least in part, to surface albedo changes as vegetation coverage changes from shrub to predominantly broadleaf and needleleaf trees (see Sect. 3.1). In the Southern Hemisphere, there is no change in temperature at the highest latitudes at $2 \times \mathrm{CO}_{2}$ because Antarctic vegetation is still almost entirely composed of shrubs and grasses. However, at $4 \times \mathrm{CO}_{2}$,

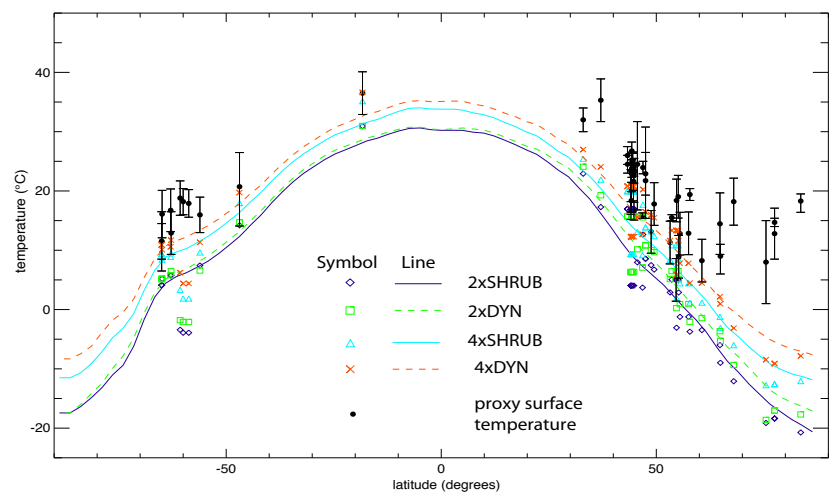

Fig. 5. As Fig. 4 but for zonal annual mean surface air temperatures. Data set from Huber and Caballero (2011), Pross et al. (2012) and Wolfe et al. (2012).

Antarctica is mostly dominated by trees, and there is a temperature increase of around $3^{\circ} \mathrm{C}$ as a result.

Modelled Arctic temperatures are too cold and modelled tropical to mid-latitude temperatures are similar to temperatures suggested by proxy data, which is consistent with the SST results. The RMSE, based on the surface air temperature (SAT) data, is $16.0^{\circ} \mathrm{C}$ for $2 \times \mathrm{SHRUB}, 11.7^{\circ} \mathrm{C}$ for $4 \times$ SHRUB, $14.6^{\circ} \mathrm{C}$ for $2 \times$ DYN and $9.5^{\circ} \mathrm{C}$ for $4 \times$ DYN . Again, the $4 \times$ DYN shows the best agreement with proxy data. However, these high-latitude temperature increases at $4 \times \mathrm{CO}_{2}$ are still insufficient to reproduce the very shallow temperature gradient indicated by available data in the high northern latitudes.

Figure 6 shows annual mean surface air temperatures. The $2 \times \mathrm{PI} \mathrm{CO}_{2}$ simulations predict colder temperatures than the data suggest at every data point. All of the $4 \times \mathrm{PI} \mathrm{CO}_{2}$ simulations in general show good agreement with data in the low and mid-latitudes, but the discrepancies increase with latitude and are largest in the Arctic.

Table 3 summarises the global mean annual SATs for all early Eocene experiments. It can be seen from this that vegetation feedbacks have a larger influence on temperature at higher $\mathrm{CO}_{2}$ concentrations, as including dynamic vegetation results in a larger temperature increase at $4 \times \mathrm{CO}_{2}\left(1.9^{\circ} \mathrm{C}\right)$ than at $2 \times \mathrm{CO}_{2}\left(1.1^{\circ} \mathrm{C}\right)$. There is a large decrease in sea ice in the Arctic in DJF between $4 \times$ SHRUB and $4 \times$ DYN, but this is not the case at $2 \times \mathrm{CO}_{2}$ (Fig. 7). Sea ice concentration in the Arctic in $2 \times$ SHRUB and $2 \times$ DYN is the same in DJF. This indicates that there are important temperature thresholds or non-linearities that are being crossed when dynamic vegetation is coupled to the model at $4 \times \mathrm{CO}_{2}$. The feedbacks resulting from this make the climate more sensitive, which is the reason why adding dynamic vegetation has a larger influence on temperature at $4 \times \mathrm{CO}_{2}$ compared with $2 \times \mathrm{CO}_{2}$. 
(a) $2 x$ SHRUB

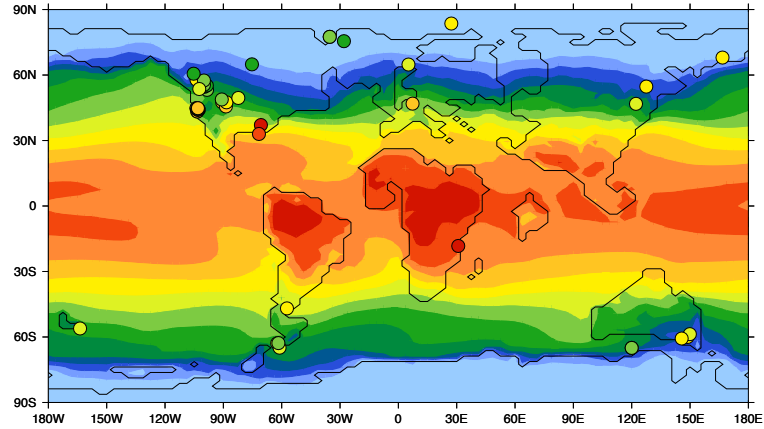

(c) $2 \mathrm{xDYN}$

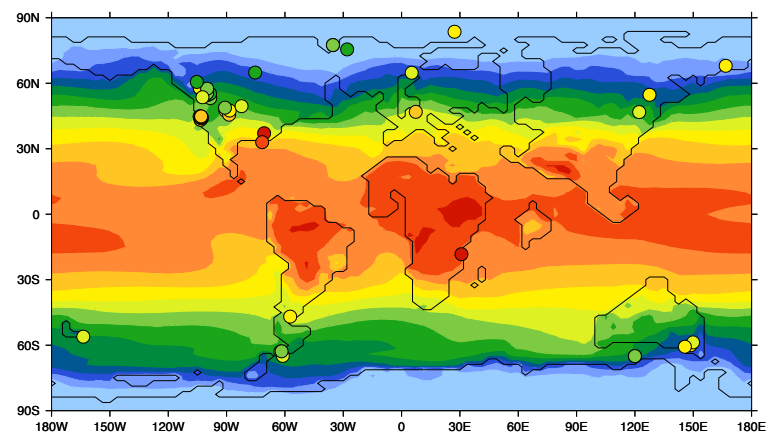

(b) $4 \times$ SHRUB

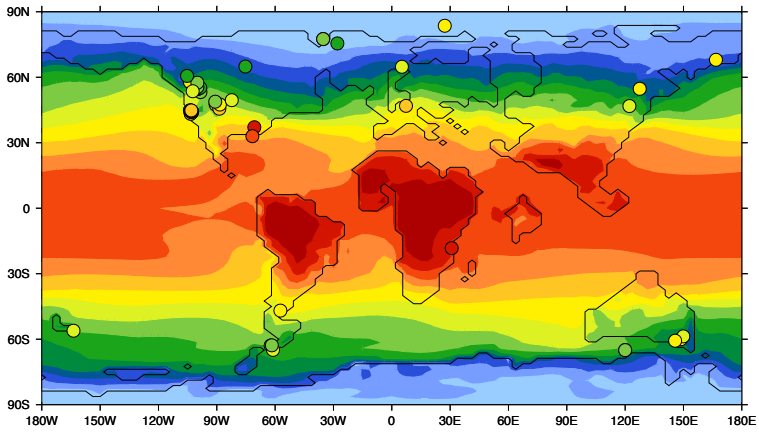

(d) $4 \mathrm{xDYN}$

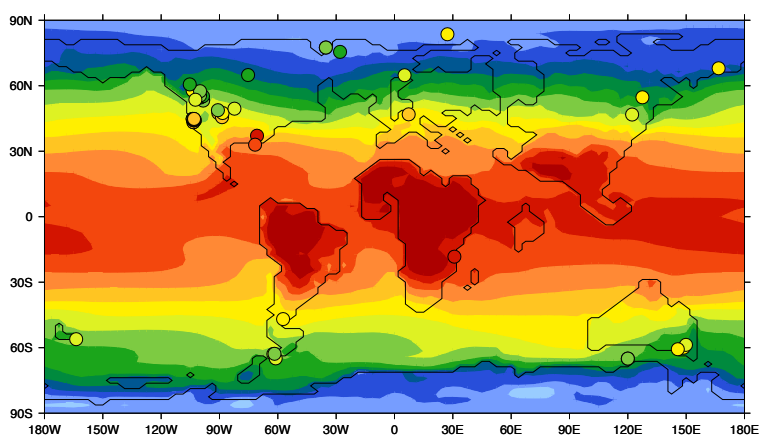

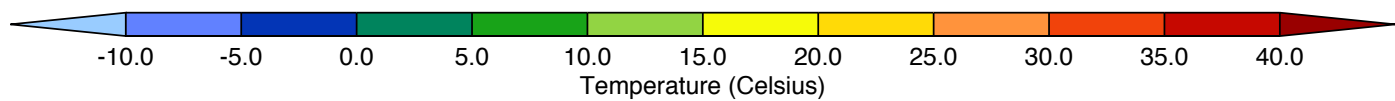

Fig. 6. Comparison of modelled global annual mean $2 \mathrm{~m}$ surface air temperature with temperatures inferred from proxy data. The circles show the temperature inferred from proxy data at the point where the data were collected. Data set from Huber and Caballero (2011), Pross et al. (2012) and Wolfe et al. (2012).

Table 3. Table showing climatological means for all Eocene experiments.

\begin{tabular}{lcccc}
\hline & & \multicolumn{3}{c}{ Global mean SAT $\left({ }^{\circ} \mathrm{C}\right)$} \\
\cline { 3 - 5 } $\begin{array}{l}\text { Experiment } \\
\text { name }\end{array}$ & $\begin{array}{c}\text { Precipitation } \\
\left(\text { mm day }^{-1}\right)\end{array}$ & Annual & DJF & JJA \\
\hline $2 \times$ SHRUB & 3.05 & 17.8 & 16.2 & 19.7 \\
$4 \times$ SHRUB & 3.19 & 21.7 & 20.2 & 23.7 \\
$2 \times$ DYN & 3.20 & 18.9 & 16.9 & 20.6 \\
$4 \times$ DYN & 3.39 & 23.6 & 22.0 & 25.6 \\
$4 \times$ FIXED & 3.27 & 22.3 & 20.6 & 24.3 \\
\hline
\end{tabular}

\subsection{Climate sensitivity}

The results from this set of simulations can also be used to investigate how climate sensitivity changes when dynamic vegetation is included in the model. Climate sensitivity can be defined as the global equilibrium temperature change in response to a doubling of atmospheric $\mathrm{CO}_{2}$.

The climate sensitivity measured with fixed vegetation only takes into account relatively short-term feedbacks and is sometimes called Charney sensitivity (Lunt et al., 2010b). Earth system sensitivity (ESS) is defined by Lunt et al. (2010b) as the climate response when long-term feedbacks are included in addition to short-term feedbacks. By adding TRIFFID, which incorporates vegetation feedbacks, a closer estimation of the ESS can be made.

Figure 8 shows the global mean surface air temperatures for all five simulations. In these simulations, the climate sensitivity increases from 3.8 to $4.8^{\circ} \mathrm{C}$ when dynamic vegetation is added. It would be expected that the climate sensitivity would be higher when vegetation feedbacks are incorporated into the model because vegetation feedbacks (e.g. albedo and hydrological) tend to be positive (Liu et al., 2006), although this is not necessarily true on a regional scale for all time periods and all models. For example, hydrological feedbacks have been found to be negative over northern Africa in the 


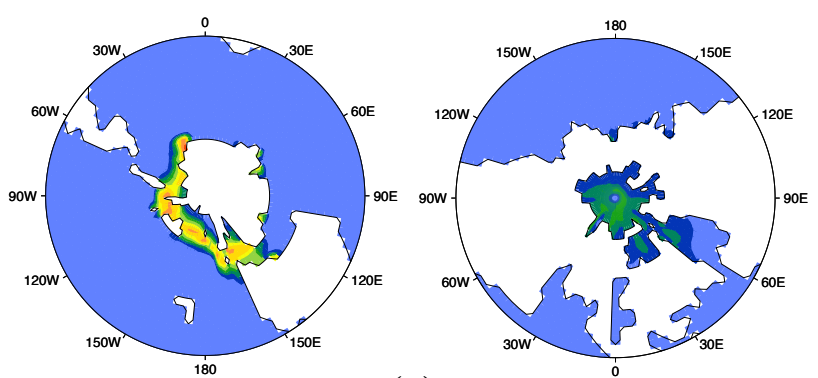

(a)

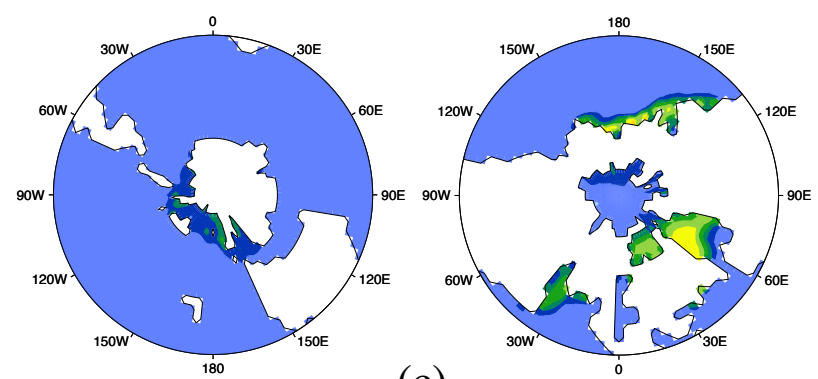

(c)

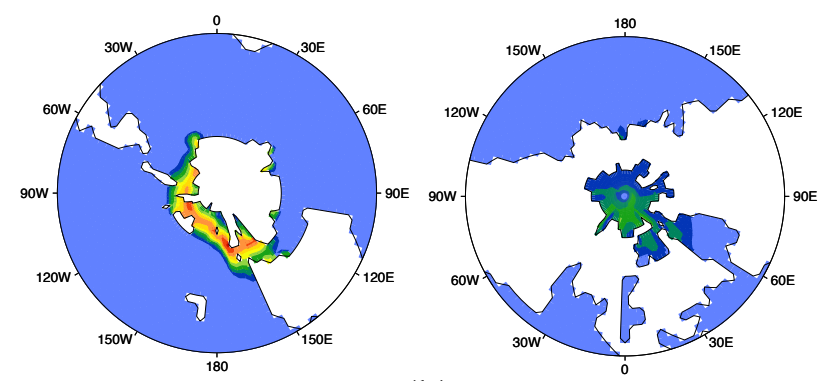

(b)

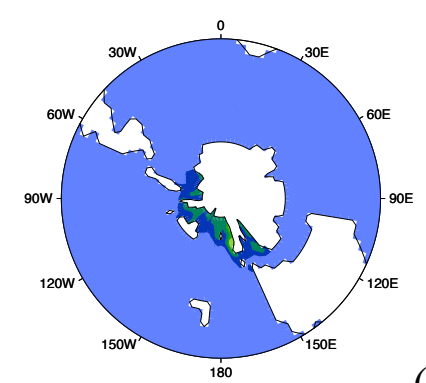

(d)

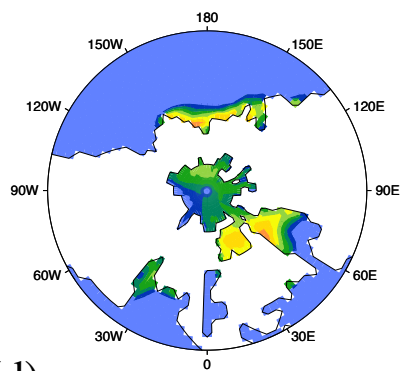

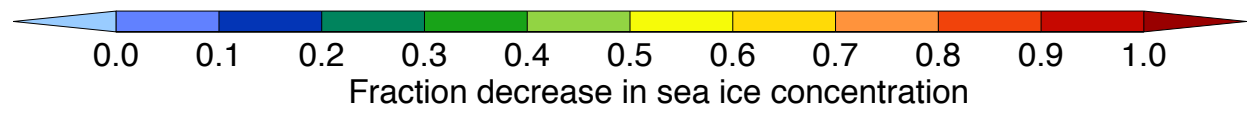

Fig. 7. Fractional reduction in sea ice concentration when $\mathrm{CO}_{2}$ is doubled in (a) SHRUB simulations in JJA, (b) DYN simulations in JJA, (c) SHRUB simulations in DJF, and (d) DYN simulations in DJF in the Southern Hemisphere (left panels) and Northern Hemisphere (right panels).

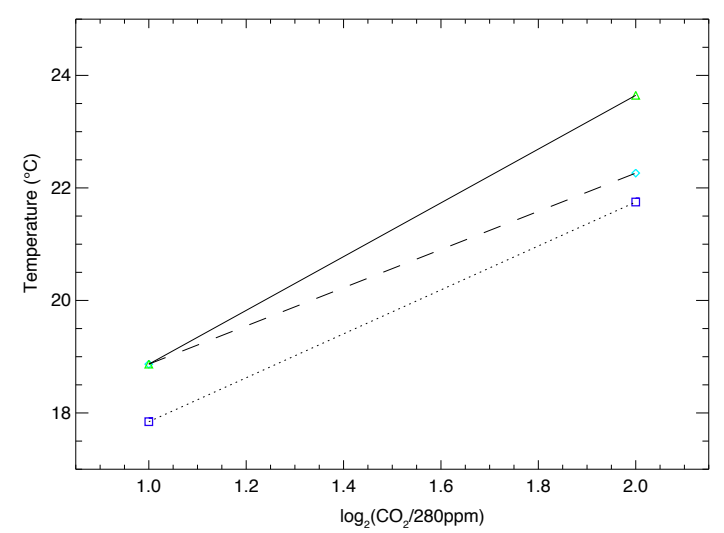

Fig. 8. Climate sensitivity measured by HadCM3L with dynamic vegetation (solid line), fixed homogeneous shrubs (dotted line) and fixed, non-homogeneous vegetation (dashed line).

Holocene in some climate models (Notaro et al., 2008; Wang et al., 2008).

When vegetation is fixed at the output of $2 \times \mathrm{DYN}$, but $\mathrm{CO}_{2}$ is doubled to $4 \times \mathrm{PI} \mathrm{CO}_{2}$ (simulation $4 \times$ FIXED), the resulting mean global annual SAT increase is $3.3^{\circ} \mathrm{C}$. This is a lower climate sensitivity than for the SHRUB and DYN simulations.

It is possible to use these mean annual temperatures (MATs) and corresponding $\mathrm{CO}_{2}$ levels to calculate the $\mathrm{CO}_{2}$ concentrations that would produce temperatures most consistent with proxy data (i.e. the $\mathrm{CO}_{2}$ level where the mean error is minimised). This calculation of "ideal" $\mathrm{CO}_{2}$ concentrations assumes that the climate sensitivity can be extrapolated linearly. This is not always the case; for example some of the models described in Lunt et al. (2012) had a climate sensitivity that increased with $\mathrm{CO}_{2}$. However, it is still a useful method for comparing the climate sensitivity of different models and provides a potential upper bound for the $\mathrm{CO}_{2}$ level that would make the model results most consistent with data. The ideal $\mathrm{CO}_{2}$ concentrations vary depending on whether the marine or terrestrial data sets are used. For the terrestrial results, the ideal $\mathrm{CO}_{2}$ values are calculated as $1720 \mathrm{ppm}$ for the DYN simulations and $2550 \mathrm{ppm}$ for the SHRUB simulations. Sea surface temperatures give ideal $\mathrm{CO}_{2}$ concentrations of $1760 \mathrm{ppm}$ for DYN and $2610 \mathrm{ppm}$ for SHRUB. These predicted atmospheric $\mathrm{CO}_{2}$ values are all in accord with the range of $\mathrm{CO}_{2}$ estimates from proxies (Beerling and Royer, 2011; Lowenstein and Demicco, 2006; Pagani et al., 2009; Sluijs et al., 2006; Pearson et al., 


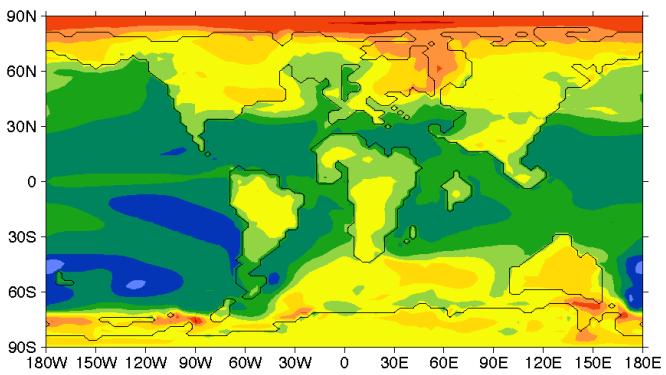

(a)

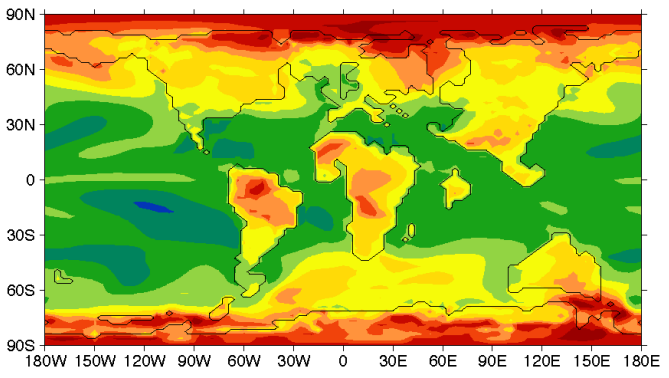

(b)

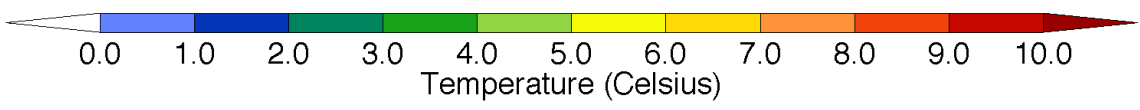

Fig. 9. Annual surface air temperature difference between (a) $4 \times$ SHRUB and $2 \times$ SHRUB and (b) $4 \times$ DYN and $2 \times$ DYN. Only differences at the $95 \%$ confidence level are shown.

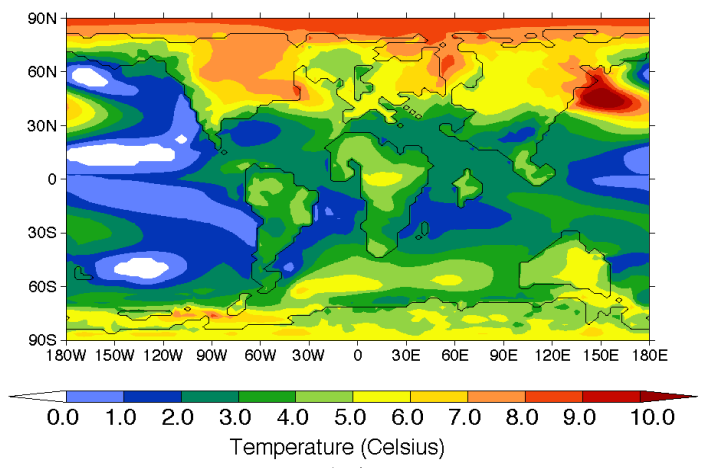

(a)

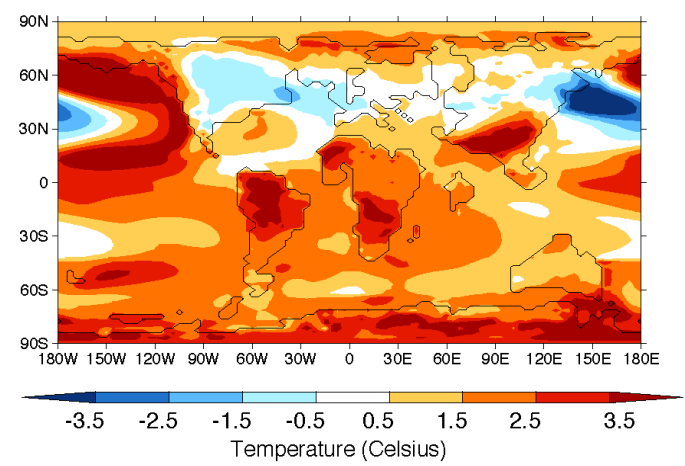

(b)

Fig. 10. Difference in annual surface air temperature when (a) $\mathrm{CO}_{2}$ is doubled but vegetation is fixed $(4 \times \mathrm{FIXED}-2 \times \mathrm{DYN})$ and $(\mathbf{b}) \mathrm{CO}_{2}$ is constant but vegetation distribution changes $(4 \times \mathrm{DYN}-4 \times$ FIXED). Only differences at the $95 \%$ confidence level are shown.

2007). The ideal $\mathrm{CO}_{2}$ values for the SHRUB simulations differ slightly from those calculated in the EoMIP study (Lunt et al., 2012), which predicts values of $2850 \mathrm{ppm}$ based on terrestrial data and $2540 \mathrm{ppm}$ based on SST data for the HadCM3L model. These differences can be attributed to the change in land surface scheme. The global annual mean SAT difference between the simulations with MOSES 2.1 and MOSES 2.2 is larger at higher $\mathrm{CO}_{2}$ concentrations, resulting in a higher climate sensitivity in the SHRUB simulations than the EoMIP HadCM3L simulations. The model is unstable at $\mathrm{CO}_{2}$ levels this high with early Eocene boundary conditions, so it is not possible to test if the model is able to produce results consistent with data at these $\mathrm{CO}_{2}$ levels.

Figure 9 shows how the temperature changes when $\mathrm{CO}_{2}$ is doubled from $2 \times$ to $4 \times \mathrm{PI} \mathrm{CO} 2$ in the SHRUB and DYN scenarios. This overall temperature increase is greater for the DYN simulations than the SHRUB simulations. Relative to SHRUB, DYN simulations show a greater decrease in sea ice extent at high latitudes when $\mathrm{CO}_{2}$ is doubled to $4 \times \mathrm{PI}$ concentrations. The resulting ice-albedo feedbacks enhance warming at high latitudes resulting in the much greater polar amplification in the DYN scenario.

\subsection{Separating effects of $\mathrm{CO}_{2}$ and vegetation on climate}

The results of the $4 \times$ FIXED simulation (the simulation at $4 \times \mathrm{PI}$ atmospheric $\mathrm{CO}_{2}$, but with the vegetation distribution of the $2 \times$ DYN simulation) can be used to determine the effect of changes in vegetation alone (by comparison with $4 \times$ DYN) and changes in atmospheric $\mathrm{CO}_{2}$ alone (by comparison with $2 \times$ DYN) on early Eocene climate.

Figure 10a shows the effects of $\mathrm{CO}_{2}$ alone on annual surface air temperature. This was calculated by taking the difference between simulations $2 \times$ DYN and $4 \times$ FIXED. It can be seen that the temperature changes are highly dependent on region. The largest temperature increases due to $\mathrm{CO}_{2}$ doubling is in the Arctic, where the global annual mean temperature increase is $8^{\circ} \mathrm{C}$, and the western Pacific, which sees a warming above $10^{\circ} \mathrm{C}$. However, there are some areas where less than $1{ }^{\circ} \mathrm{C}$ of warming occurs, such as some parts of the Pacific Ocean. 


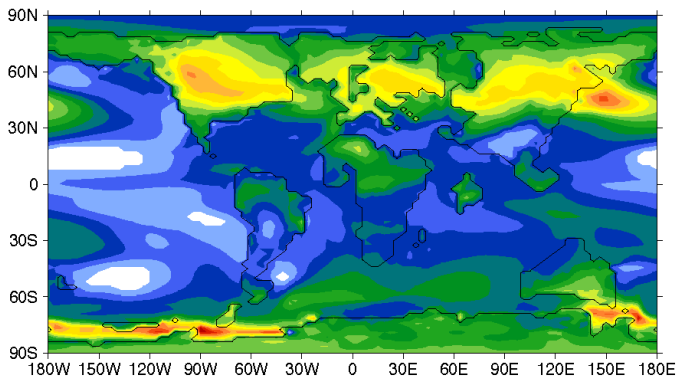

(a)

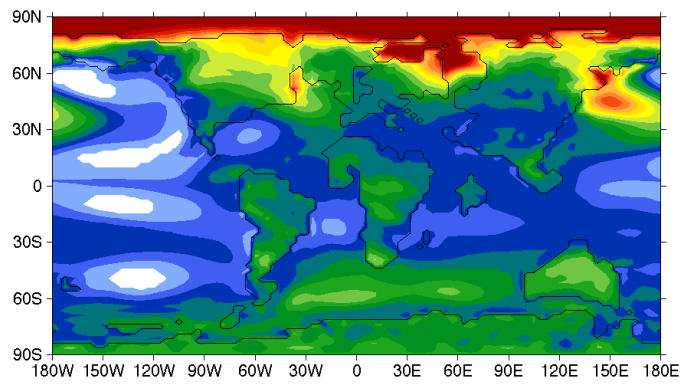

(b)

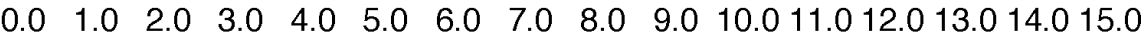 Temperature (Celsius)}

Fig. 11. Surface air temperature differences when $\mathrm{CO}_{2}$ is doubled from $2 \times$ to $4 \times$ (i.e. $4 \times$ FIXED $-2 \times$ DYN) (a) in JJA and (b) in DJF. Only differences at the $95 \%$ confidence level are shown.

Changes in temperature due to vegetation changes between $4 \times$ FIXED and $4 \times$ DYN are shown in Fig. 10b. These vegetation changes account for a global annual average temperature increase of $1.3^{\circ} \mathrm{C}$. However, they do not result in warming everywhere on a regional scale. A small decrease $\left(\sim 1^{\circ} \mathrm{C}\right)$ in temperature can be seen over some regions of land in the mid-latitudes of the Northern Hemisphere, specifically over North America and Asia. In the Southern Hemisphere, the temperature increase is as much as $5^{\circ} \mathrm{C}$, which is similar in magnitude to the warming in these same regions when $\mathrm{CO}_{2}$ is doubled. The Northern Hemisphere shows cooling and Southern Hemispheres shows warming behaviour because of the different vegetation changes. In the Northern Hemisphere, shrubs and broadleaf trees replace needleleaf trees, whereas on Antarctica trees replace shrubs. This means that the surface albedo increases across North America and the albedo decreases over Antarctica. The areas of highest temperature increase in the tropics correlate with the areas of increased bare soil coverage (see Figs. 1 and 2).

\subsection{Seasonality}

The influence of $\mathrm{CO}_{2}$ and vegetation on climate are dependent on the season. Figures 11 and 12 show how these factors change the surface air temperature in the Northern Hemisphere summer months (JJA) and in the winter months (DJF). Global mean surface air temperatures are shown in Table 3.

Vegetation changes alone result in a global average temperature increase of $1.7^{\circ} \mathrm{C}$ in DJF and $1.6^{\circ} \mathrm{C}$ in JJA. Doubling $\mathrm{CO}_{2}$ alone results in global average temperature increases of $3.6^{\circ} \mathrm{C}$ in DJF and $3.4^{\circ} \mathrm{C}$ in JJA, more than twice as large as the impact of vegetation changes. The reasons behind these differences in temperature increase are explained in more detail in Sect. 3.8.

Figure 11 shows that doubling $\mathrm{CO}_{2}$ without changing vegetation has the largest effect on temperature in the Arctic in
DJF, where the temperature increase is more than $15^{\circ} \mathrm{C}$ in some areas. This is due to a decrease in winter sea ice cover (as a result of warming due to increased $\mathrm{CO}_{2}$ ) and associated albedo-ice feedbacks. This is also the mechanism behind the large temperature increase in some regions off the coast of Antarctica in JJA, but the change is smaller in magnitude and area than the Arctic.

In addition, a temperature increase of $8-9{ }^{\circ} \mathrm{C}$ is seen in the mid-latitudes of the Northern Hemisphere in JJA. This is a result of increased atmospheric water vapour and differences in albedo due to changes in cloud cover. There is reduced cloud cover in these regions, especially at low levels, in JJA but high-level cloud cover increases in these regions in DJF (not shown). The reduction in high-level cloud in JJA results in a decreased albedo, which contributes to the warmer temperatures relative to DJF in these regions. See Sect. 3.8 for further discussion of how water vapour and cloud cover contribute to the overall temperature difference. These changes are associated with enhanced vegetation feedbacks as a result of higher atmospheric $\mathrm{CO}_{2}$ concentrations.

Vegetation has the greatest effect on temperature over terrestrial equatorial regions in JJA, where the extent of bare soil increases, and at high latitudes in DJF, where trees replace grasses and shrubs (Fig. 12). In JJA, the regions of greatest warming over land are associated with regions of reduced evapotranspiration (see Fig. 13) and soil moisture. Although vegetation changes result in a temperature increase when looking at the global mean, these vegetation differences result in a slight cooling effect in the mid-latitudes of the Northern Hemisphere, especially in summer. This is primarily due to differences in surface albedo, where broadleaf trees and shrubs replace needleleaf trees.

Figure 14 shows the effect of dynamic vegetation on surface air temperature increase when $\mathrm{CO}_{2}$ is doubled, i.e. $(4 \times$ DYN $-2 \times$ DYN $)-(4 \times$ SHRUB $-2 \times$ SHRUB $)$, 


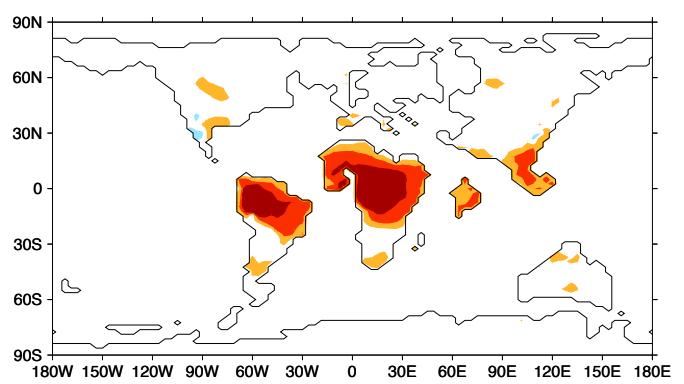

(a)

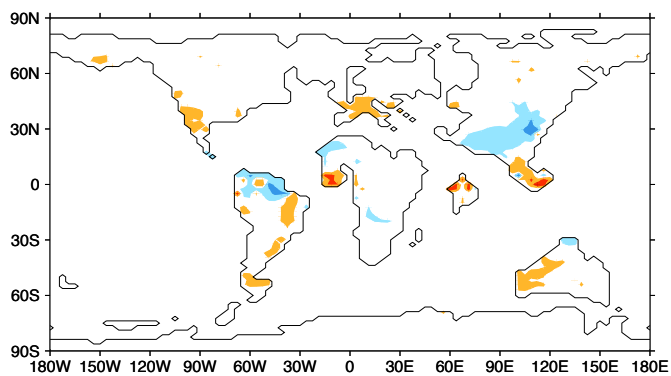

(c)

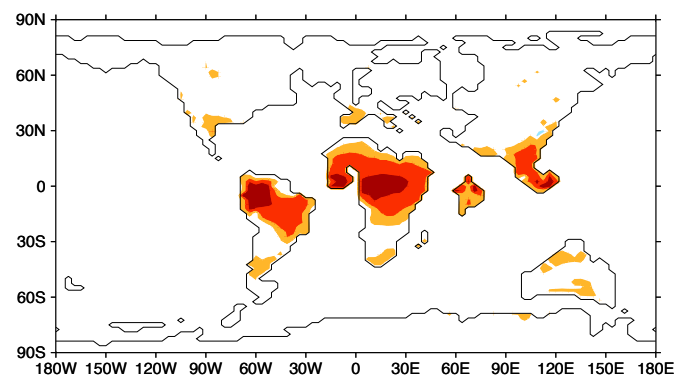

(b)

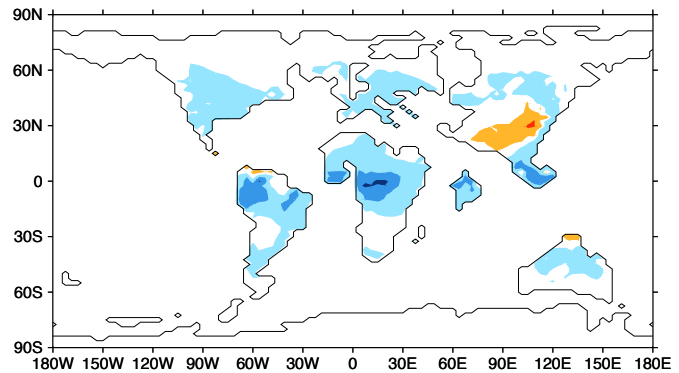

(d)

Fig. 12. Surface air temperature differences when vegetation distribution is changed from that of $2 \times \mathrm{DYN}$ to $4 \times \mathrm{DYN}^{\mathrm{N}}$ but with $\mathrm{CO}_{2}$ constant at $4 \times$ (i.e. $4 \times$ DYN $-4 \times$ FIXED) (a) in JJA and (b) in DJF. Only differences at the $95 \%$ confidence level are shown.

in JJA and DJF. These figures show that the strongest differences in seasonal climate are at high latitudes in DJF.

The Arctic shows a large temperature difference in DJF, but not in JJA. This is a result of ice-albedo feedbacks that occur due to a larger reduction in winter sea ice when $\mathrm{CO}_{2}$ is doubled with dynamic vegetation compared to homogeneous shrubs. There is no evidence for any sea ice in the early Eocene; however it is present in our model. This is likely a consequence of temperatures being too low at high latitudes. If the temperatures at high latitudes matched those indicated by proxy data, then it is likely seasonality would be reduced due to a lack of sea ice.

In the Southern Hemisphere, the largest warming also occurs in DJF, i.e. austral summer. There is limited incoming solar radiation over Antarctica in JJA, so changes in albedo between $2 \times$ DYN and $4 \times$ DYN (due to the change in vegetation coverage from mainly grasses and shrubs to trees) would have no effect on temperature in these months but would have an effect in DJF. This increase in SAT due to these surface albedo changes results in an increase in humidity. These water vapour feedbacks amplify the temperature increase. In addition, the net primary productivity (NPP) is almost identical over Antarctica in JJA for
$2 \times$ DYN and $4 \times$ DYN, but in DJF NPP it increases by over $0.2 \mathrm{kgC} \mathrm{m}^{-2} \mathrm{yr}^{-1}$. This increase in plant productivity means that the water vapour feedbacks associated with vegetation would be strongest in DJF.

\subsection{Ocean dynamics}

Figure 15 shows the global annual meridional overturning circulation (MOC) for each simulation. At low $\mathrm{CO}_{2}$, the MOC is characterised by a strong negative overturning cell. It is stronger at $2 \times \mathrm{CO}_{2}$ compared with $4 \times \mathrm{CO}_{2}$ in both the SHRUB and DYN simulations. This is consistent with the results of Lunt et al. (2010a), who also found that the strength of the MOC decreases between $2 \times \mathrm{CO}_{2}$ and $4 \times \mathrm{CO}_{2}$ using HadCM3L. The DYN simulations have a weaker (less negative) MOC than the SHRUB simulations, especially in the Southern Hemisphere. This weakening of the MOC between SHRUB and DYN is inconsistent with the findings of Lohmann et al. (2006), who simulated the late Miocene climate and found the the MOC increased in strength when the vegetation became more lush and the coverage of trees increased. In the $4 \times$ FIXED simulation this overturning cell has disappeared, and has been replaced with a very weak 


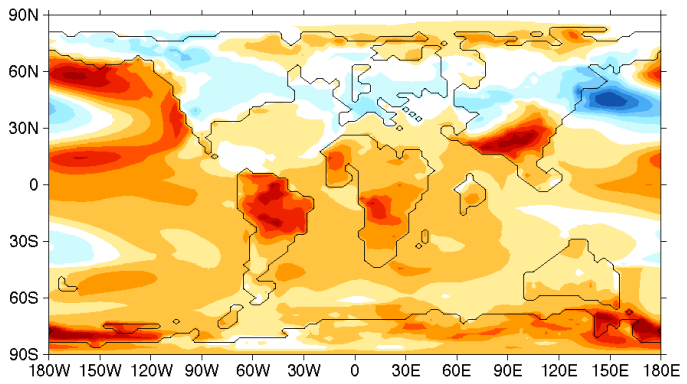

(a)

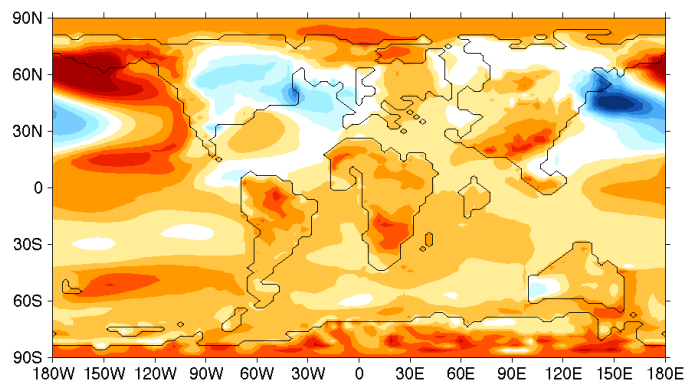

(b)

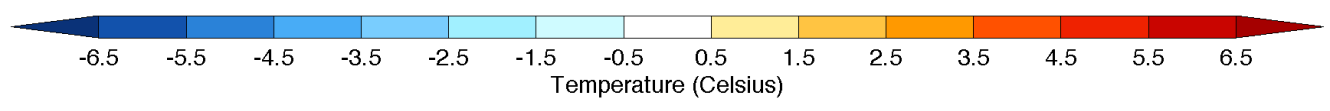

Fig. 13. Daily evapotranspiration difference between (a) $2 \times$ DYN and $2 \times$ SHRUB, (b) $4 \times$ DYN and $4 \times$ SHRUB, (c) $4 \times$ DYN and $4 \times$ FIXED, and (d) $4 \times$ FIXED and $2 \times$ DYN .

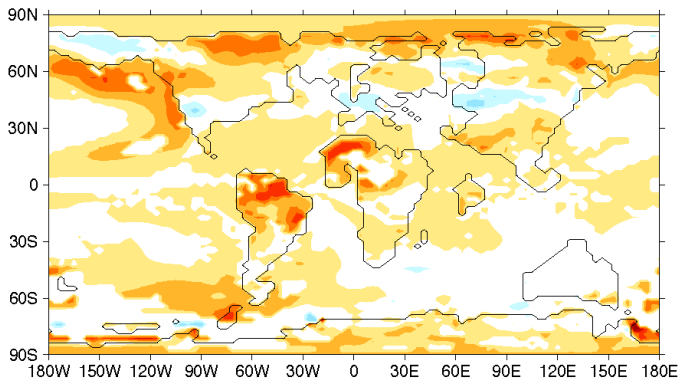

(a)

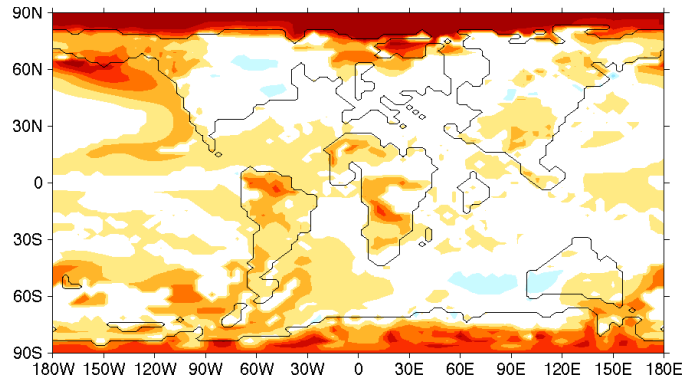

(b)

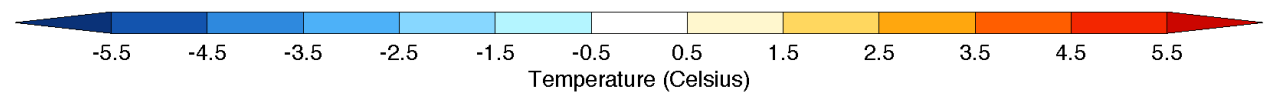

Fig. 14. The effect of dynamic vegetation on the surface air temperature increase when $\mathrm{CO}_{2}$ is doubled (i.e. $4 \times \mathrm{DYN}-2 \times \mathrm{DYN})-(4 \times \mathrm{SHRUB}-2 \times \mathrm{SHRUB})$ (a) in JJA and (b) in DJF. Only differences at the $95 \%$ confidence level are shown.

MOC in the opposite (positive) direction. The depth of the MOC is much shallower in the $4 \times$ FIXED simulation compared to the other simulations.

Regions of deep water formation also differ between simulations. As the MOC weakens, deep water formation in the Southern Ocean between 180 and $60^{\circ} \mathrm{W}$ is reduced and intensifies between $30^{\circ} \mathrm{W}$ and $30^{\circ} \mathrm{E}$ (not shown).

The equatorial current in the western Pacific Ocean is much stronger in $4 \times$ FIXED than in any of the SHRUB or DYN simulations (not shown). This stronger equatorial current leads to the western boundary current extending poleward and warmer, more saline (with a difference of 5 PSU between $4 \times$ FIXED and $2 \times$ DYN) waters reaching higher latitudes along the eastern coast of Asia. This warm current accounts for the large temperature increase in the western $\mathrm{Pa}$ cific Ocean (Fig. 10a). These changes in the MOC and western boundary current are also seen by Zhou et al. (2012) in their simulations of warm mid-Cretaceous climate.

\subsection{Precipitation differences}

Vegetation affects the hydrological cycle, so it would be expected that adding dynamic vegetation will affect precipitation distributions and magnitudes. Annual global means for precipitation are shown in Table 3.

Adding dynamic vegetation to the simulations does enhance the hydrological cycle. Compared to the shrub simulations, the simulations with TRIFFID have precipitation rates $4.9 \%$ higher at $2 \times$ and $6.3 \%$ higher at $4 \times \mathrm{PI} \mathrm{CO}_{2}$. Increasing $\mathrm{CO}_{2}$ also increases total annual precipitation for a given vegetation scheme. When atmospheric $\mathrm{CO}_{2}$ concentrations are increased from $2 \times$ to $4 \times$, global mean rainfall rates increase by $4.6 \%$ with fixed homogeneous shrubs (Fig. 16a) and $5.9 \%$ in the simulations where TRIFFID is included (Fig. 16b). By comparison with the $4 \times$ FIXED simulation, it can be seen that this increase in total precipitation between 


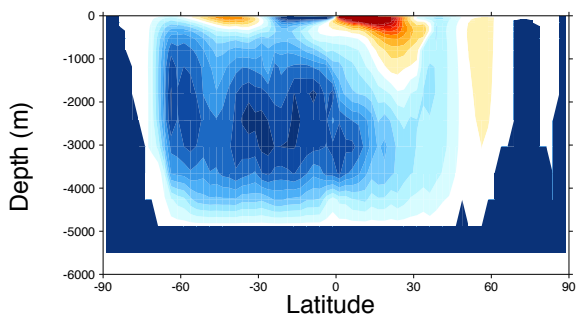

(a)

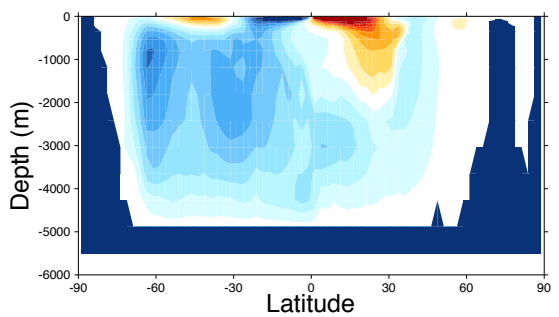

(b)

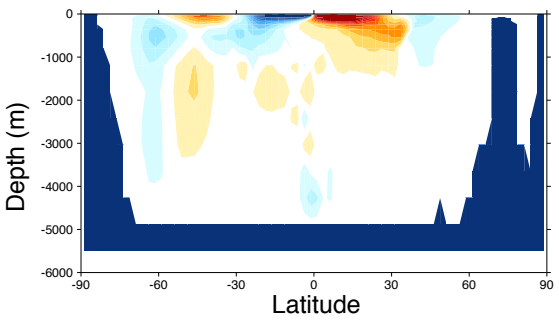

(c)

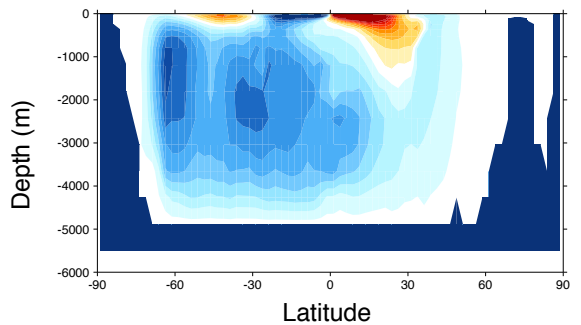

(d)

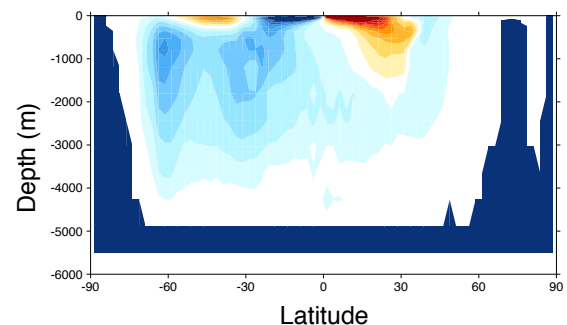

(e)

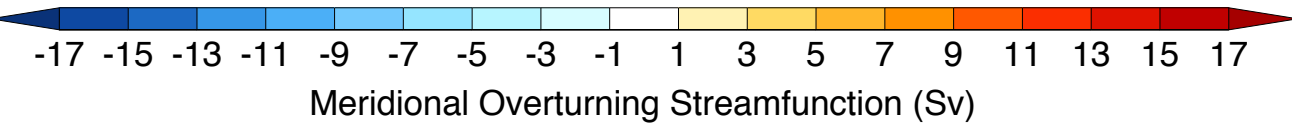

Fig. 15. Global annual meridional overturning stream function for (a) $2 \times$ SHRUB, (b) $4 \times$ SHRUB, (c) $4 \times$ FIXED, (d) $2 \times$ DYN and (e) $4 \times$ DYN. Positive values indicate clockwise circulation and negative values indicate anticlockwise circulation.

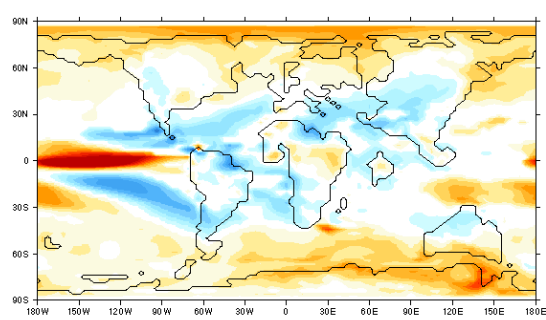

(a)

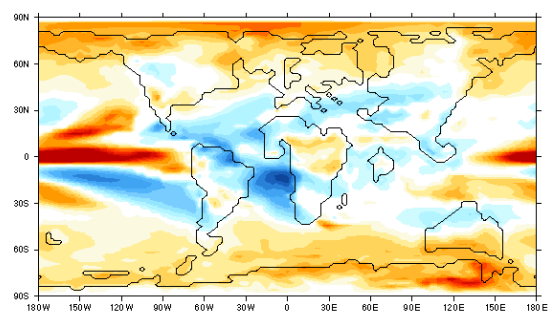

(b)

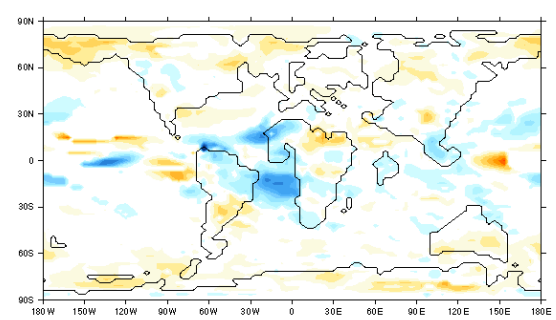

(c)

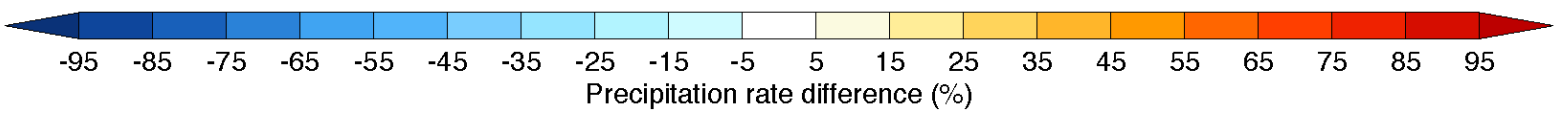

Fig. 16. Percentage change in annual precipitation between (a) $4 \times$ SHRUB and $2 \times$ SHRUB, and between (b) $4 \times$ DYN and $2 \times$ DYN, while (c) shows the effect of dynamic vegetation on the precipitation difference when $\mathrm{CO}_{2}$ is doubled, i.e. the difference between (a) and (b). Only differences at the $95 \%$ confidence level are shown.

$2 \times$ DYN and $4 \times$ DYN is mostly due to the change in climate rather than the change in vegetation.

When dynamic vegetation is included in the model, the band of enhanced precipitation across the equatorial Pacific Ocean covers a larger area relative to the simulations with homogeneous shrubs. However, precipitation rates show a large percentage decrease (up to $100 \%$ ) in the South Atlantic Ocean when TRIFFID is included in the model. This is much larger than the simulations with fixed shrubs, which sees a decrease of around $20 \%$ in this same region.
The areas over land where there is a decrease of 20 to $40 \%$ in precipitation in Fig. 16b correlate with areas of bare soil in the $4 \times$ DYN simulation. Areas of percentage decrease in precipitation are also associated with areas where shrubs replace trees as the dominant PFT around areas of bare soil. The percentage increases in precipitation rates at high latitudes are enhanced slightly in the simulations with TRIFFID compared with the SHRUB simulations. 
Table 4. Summary of the 1-D energy balance analysis. The total global MAT difference is denoted by $\Delta T, \Delta T_{\text {lwc }}$ is the component of $\Delta T$ due to longwave cloud changes (i.e. changes in emissivity due to clouds), $\Delta T_{\mathrm{gg}}$ is the component due to greenhouse gases, $\Delta T_{\mathrm{swc}}$ is the shortwave cloud contribution (i.e. changes in albedo due to clouds) and $\Delta T_{\text {salb }}$ is the contribution of planetary surface albedo changes. The contribution from each factor as a percentage of $\Delta T$ is shown in brackets. All temperatures are in degrees Celsius.

\begin{tabular}{lrrccr}
\hline Experiment names & $\Delta T$ & $\Delta T_{\mathrm{lwc}}$ & $\Delta T_{\mathrm{gg}}$ & $\Delta T_{\mathrm{swc}}$ & $\Delta T_{\text {salb }}$ \\
\hline $4 \times$ SHRUB $-2 \times$ SHRUB & 3.8 & $-0.5(-14.3 \%)$ & $3.5(91.6 \%)$ & $0.7(17.3 \%)$ & $0.3(7.0 \%)$ \\
$4 \times$ DYN $-2 \times$ DYN & 4.8 & $-0.6(-11.8 \%)$ & $4.2(87.2 \%)$ & $1.0(20.2 \%)$ & $0.2(4.8 \%)$ \\
$2 \times$ DYN $-2 \times$ SHRUB & 1.1 & $-0.0(-4.0 \%)$ & $0.5(50.1 \%)$ & $0.1(11.0 \%)$ & $0.5(49.6 \%)$ \\
$4 \times$ DYN $-4 \times$ SHRUB & 2.0 & $-0.1(-2.9 \%)$ & $1.2(59.6 \%)$ & $0.4(21.1 \%)$ & $0.5(23.8 \%)$ \\
$4 \times$ FIXED $-2 \times$ DYN & 3.3 & $-0.6(-17.8 \%)$ & $3.2(95.3 \%)$ & $0.7(20.8 \%)$ & $0.2(5.7 \%)$ \\
$4 \times$ DYN $-4 \times$ FIXED & 1.1 & $0.1(5.3 \%)$ & $0.8(72.3 \%)$ & $0.2(16.9 \%)$ & $-0.1(-10.8 \%)$ \\
\hline
\end{tabular}

\subsection{Energy balance analysis}

Traditionally it has been difficult to diagnose which processes are responsible for the differences in surface air temperature between two different simulations. By analysing radiation fluxes instead of just looking at surface temperatures within each grid box, changes in temperature can be attributed to different mechanisms within the climate system. This is because changes in a given aspect of the planet or atmosphere will only affect certain fluxes (e.g. changes in albedo affect shortwave radiation fluxes, whereas changes in greenhouse gases only affect longwave radiation). These changes in radiation fluxes can be converted into temperature differences using the energy balance model.

Lunt et al. (2012) have included additional diagnostics to the energy balance analysis detailed in Heinemann et al. (2009) to show the extent to which changes in five different aspects of the planet and atmosphere (heat transport, emissivity due to clouds, emissivity due to greenhouse gases, albedo of clouds and albedo of planetary surface) contribute to the overall temperature difference between GCM simulations. The full details of the energy balance calculations used here can be found in Lunt et al. (2012).

It should be noted that the temperature difference due to changes in albedo of planetary surface also include changes in atmospheric effects (i.e. how much radiation is scattered by the atmosphere). However, this only needs to be taken into account when the thickness of the atmosphere or orographic height at a grid point varies between simulations (e.g. comparing a pre-industrial simulation with an early Eocene simulation). This is not the case in these comparisons, so the difference in atmospheric effects is negligible.

Table 4 summarises the global mean energy balance analysis results. The climate sensitivity is lower for the FIXED simulations (i.e. $4 \times$ FIXED $-2 \times$ DYN) than the SHRUB simulations mainly due to GHG emissivity, resulting in $0.3^{\circ} \mathrm{C}$ less warming. The differences in planetary surface albedo between $2 \times$ and $4 \times$ result in $0.1^{\circ} \mathrm{C}$ less warming in the $4 \times$ FIXED case compared to the SHRUB simulations. The emissivity due to clouds is also different in the FIXED and SHRUB cases. It acts to cool the climate for both vegetation distributions but has a lesser cooling effect when $\mathrm{CO}_{2}$ is doubled in the SHRUB case. This is because, globally, there is a smaller cloud cover difference between $4 \times$ FIXED and $2 \times$ DYN than between $4 \times$ SHRUB and $2 \times$ SHRUB.

The one-dimensional (i.e. zonal mean) energy balance analysis for a doubling of $\mathrm{CO}_{2}$ from $2 \times$ to $4 \times \mathrm{PI} \mathrm{CO}_{2}$ is shown in Fig. 17. Figure 17a is for the homogeneous shrub case, and so excludes vegetation feedbacks, whereas Fig. 17b shows the different contributions to the temperature change when vegetation feedbacks are included.

In both of these cases, emissivity due to greenhouse gases is the largest contributing factor to the overall temperature increase. However, the contribution is $0.7{ }^{\circ} \mathrm{C}$ larger for the simulation with interactive vegetation compared to fixed uniform vegetation. Since the change in $\mathrm{CO}_{2}$ is the same in both cases, it means that there is a higher concentration of another greenhouse gas in the atmosphere (water vapour) when HadCM3L is coupled to TRIFFID.

When $\mathrm{CO}_{2}$ is doubled, the increase in total evaporation is over $50 \%$ larger for the dynamic vegetation simulations and specific humidity is higher than when the land surface is covered with shrubs only. This a result of higher temperatures in the DYN simulations and hydrological recycling due to vegetation. These hydrological feedbacks may be driven by the change in surface albedo due to the altered vegetation distribution. In addition, the DYN simulations show reduced subsurface runoff compared to the SHRUB simulations. This is due to the coverage of broadleaf trees in the DYN simulations, as the root systems of broadleaf trees in TRIFFID are more effective at retaining water than shrubs.

In both Fig. 17a and b, the polar amplification of warming is apparent. The high latitudes increase in temperature more than the Equator by 3 and $4{ }^{\circ} \mathrm{C}$, respectively. The surface albedo effect becomes more important in Antarctica for the DYN simulations, with $2{ }^{\circ} \mathrm{C}$ more warming at the highest southern latitudes compared to the SHRUB simulations. This is consistent with the vegetation coverage, which changes in DYN but not in SHRUB between $2 \times \mathrm{CO}_{2}$ and $4 \times \mathrm{CO}_{2}$. Changes in cloud albedo result in a larger (i.e. less negative) contribution to total temperature change in the Arctic in the 


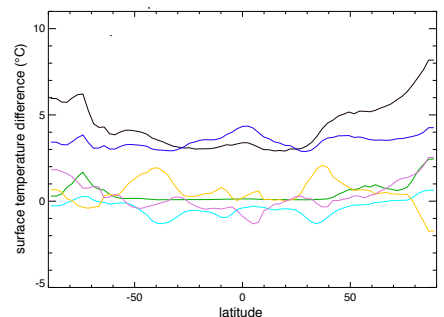

(a)

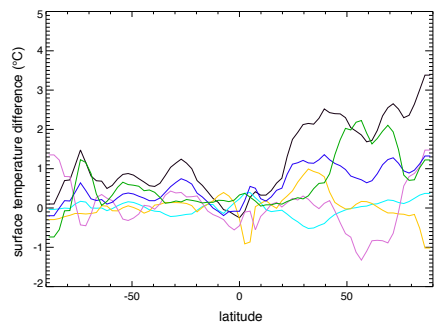

(c)

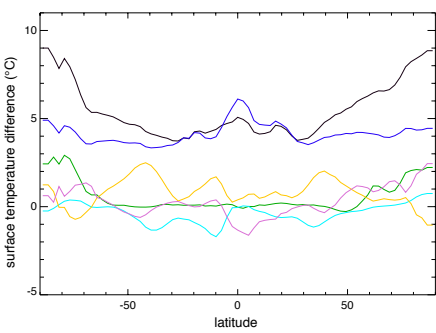

(b)

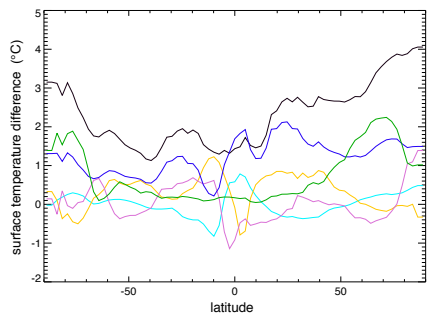

(d)
Key

EBM

emissivity due to clouds

emissivity due to greenhouse gases

albedo due to clouds

albedo due to atmosphere and surface

due to heat transport

Fig. 17. Contributions from different factors to the annual mean temperature differences when $\mathrm{CO}_{2}$ in doubled, determined through energy balance model analysis for (a) shrubs everywhere and (b) TRIFFID turned on, and when land surface coverage changes from shrubs everywhere to the vegetation distribution predicted by TRIFFID determined through energy balance model analysis at (c) $2 \times$ and (d) $4 \times$ PI $\mathrm{CO}_{2}$.

DYN simulations compared to SHRUB, where total cloud cover decreases. Heat transport to the high latitudes is reduced in the DYN simulations compared to the SHRUB simulations. This result is consistent with other studies, e.g. Sagoo et al. (2013), that have found a reduction in ocean heat transport as tropical SSTs increase.

Figure $17 \mathrm{c}$ and $\mathrm{d}$ show the change in temperature when TRIFFID is coupled to the GCM, compared with prescribed homogeneous shrubs covering all land. It can be seen that, as $\mathrm{CO}_{2}$ increases, the vegetation distribution has a larger effect on temperature. At $4 \times \mathrm{PI} \mathrm{CO}_{2}$, the overall temperature increase is almost double that of the $2 \times \mathrm{PI} \mathrm{CO}_{2}$ simulations. This is due to an increase in GHG and cloud albedo effects (see Table 4). The temperature increase due to GHGs more than doubles between Fig. 17c and d. This is consistent with water vapour feedbacks becoming enhanced as $\mathrm{CO}_{2}$ concentrations increase.

The change in vegetation distribution has a much larger effect in Antarctica at $4 \times \mathrm{CO}_{2}$ compared to $2 \times \mathrm{CO}_{2}$. This is mainly due to a $2{ }^{\circ} \mathrm{C}$ temperature increase in the contribution of surface albedo and water vapour. This is consistent with the differences in predicted vegetation distributions; the $2 \times$ DYN simulation still has quite high coverage of shrubs on Antarctica, whereas broadleaf trees dominate almost the entire continent in $4 \times$ DYN. The effect of albedo due to clouds is amplified in the tropics at $4 \times \mathrm{CO}_{2}$ relative to $2 \times \mathrm{CO}_{2}$. There is a larger decrease in high-level cloud cover between DYN simulations compared to the SHRUB simulations in the tropics, which results in the higher peak at around $10^{\circ} \mathrm{S}$. Cloud albedo effects also contribute $\sim 1^{\circ} \mathrm{C}$ more to the overall temperature difference at the highest northern latitudes, where there is increased cloud cover.

\section{Conclusions}

This paper has investigated how the vegetation distributions predicted by TRIFFID vary with atmospheric $\mathrm{CO}_{2}$, and how these changes in vegetation affect the climate and climate sensitivity. It has also investigated the reasons behind the temperature differences between simulations using an energy balance model.

The strongest warming when $\mathrm{CO}_{2}$ is doubled is seen in the Arctic and is due to ice-albedo feedbacks. These feedbacks are stronger with dynamic vegetation than with shrubs everywhere, as the vegetation feedbacks enhance initial warming which triggers more ice melt.

Dynamic vegetation enhances the hydrological cycle, which is consistent with previous studies (e.g. Liu et al., 2006). The DYN simulations have higher precipitation rates than SHRUB for a given atmospheric $\mathrm{CO}_{2}$ level and show a larger increase when $\mathrm{CO}_{2}$ is doubled.

Including a dynamic vegetation component to the model increases global temperatures, mainly through water vapour feedbacks, and goes some way to resolving the model-data discrepancies. The $4 \times$ DYN simulation is most consistent with data, in terms of both predicted vegetation and modelled temperatures. However, model-data discrepancies still exist, especially at high latitudes, for all model scenarios described here. The modelled latitudinal temperature gradient is too steep, with high latitudes not reaching the warmth 
predicted by proxy data. The paucity of data, especially in the Arctic and Antarctica, makes it challenging to discern the extent of the model-data discrepancies at high latitudes. However, it can be concluded that vegetation feedbacks alone are not enough to explain the model-data temperature mismatch. There could be processes that are poorly represented or not present in the model and/or with data (e.g. seasonal bias, high-latitude clouds).

The DYN simulations have a smaller RMSE than the SHRUB simulations for a given $\mathrm{CO}_{2}$ level when compared with temperatures inferred from proxy data. As a result of the higher temperatures and climate sensitivity in the DYN simulations, they also have a lower ideal $\mathrm{CO}_{2}$ value. This means that vegetation feedbacks can explain, to some extent, how the early Eocene warmth could be consistent with atmospheric $\mathrm{CO}_{2}$ levels at the lower end of the estimated range (Beerling and Royer, 2011; Lowenstein and Demicco, 2006; Pagani et al., 2009; Sluijs et al., 2006; Pearson et al., 2007).

In future simulations, TRIFFID should be adapted to be more appropriate for the early Eocene. This could be done by replacing $\mathrm{C}_{4}$ with a vegetation type that is known to exist in this time period, such as ferns (Donnadieu et al., 2009). In addition, parameters of other PFTs within TRIFFID could be adjusted to be more consistent with palaeovegetation, as the model currently uses modern-day parameter values and it is possible that these values have changed over time. This could give a more realistic vegetation representation for the modelled early Eocene climate.

Acknowledgements. This work was funded by NERC grant number $\mathrm{NE} / \mathrm{I005722/1}$ and is part of the PALEOPOLAR project within the "Co-Evolution of Life and the Planet" programme.

Edited by: G. Chen

\section{References}

Beerling, D. J. and Royer, D. L.: Convergent Cenozoic $\mathrm{CO}_{2}$ history, Nat. Geosci., 4, 418-420, 2011.

Beerling, D. J., Fox, A., Stevenson, D. S., and Valdes, P. J.: Enhanced chemistry-climate feedbacks in past greenhouse worlds, P. Natl. Acad. Sci., 108, 9770-9775, doi:10.1073/pnas.1102409108, 2011.

Bijl, P. K., Schouten, S., Sluijs, A., Reichart, G., Zachos, J. C., and Brinkhuis, H.: Early Palaeogene temperature evolution of the southwest Pacific Ocean, Nature, 461, 776-779, 2009.

Bonan, G. B.: Forests and Climate Change: Forcings, Feedbacks, and the Climate Benefits of Forests, Science, 320, 1444-1449, 2008.

Bonan, G. B., Levis, S., Sitch, S., Vertenstein, M., and Oleson, K. W.: A dynamic global vegetation model for use with climate models: concepts and description of simulated vegetation dynamics, Global Change Biol., 9, 1543-1566, 2003.

Cantrill, D. J., Tosolini, A.-M. P., and Francis, J. E.: Paleocene flora from Seymour Island, Antarctica: revision of Dusén's (1908) pteridophyte and conifer taxa, Alcheringa, 35, 309-328, 2011.
Christin, P.-A., Osborne, C. P., Sage, R. F., Arakaki, M., and Edwards, E. J.: $\mathrm{C}_{4}$ eudicots are not younger than $\mathrm{C}_{4}$ monocots, $\mathrm{J}$. Exp. Bot., 62, 3171-3181, 2011.

Contreras, L., Pross, J., Bijl, P. K., Koutsodendris, A., Raine, J. I., van de Schootbrugge, B., and Brinkhuis, H.: Early to Middle Eocene vegetation dynamics at the Wilkes Land Margin (Antarctica), Rev. Palaeobot. Palynol., 197, 119-142, 2013.

Cox, P. M.: Description of the "TRIFFID" Dynamic Global Vegetation Model, Tech. Rep. Hadley Centre Technical Note 24, Meteorological Office, Bracknell, Berkshire, 2001.

Cox, P. M., Huntingford, C., and Harding, R. J.: A canopy conductance and photosynthesis model for use in a GCM land surface scheme, J. Hydrol., 212-213, 79-94, 1998.

Cox, P. M., Betts, R., Bunton, C. B., Essery, R. L. H., Rowntree, P. R., and Smith, J.: The impact of new land surface physics on the GCM simulation of climate and climate sensitivity, Clim. Dynam., 15, 183-203, 1999.

Donnadieu, Y., Goddéris, Y., and Bouttes, N.: Exploring the climatic impact of the continental vegetation on the Mezosoic atmospheric $\mathrm{CO}_{2}$ and climate history, Clim. Past, 5, 85-96, doi:10.5194/cp-5-85-2009, 2009.

Eberle, J. J. and Greenwood, D. R.: Life at the top of the greenhouse Eocene world - A review of the Eocene flora and vertebrate fauna from Canada's High Arctic, Geol. Soc. Am. Bull., 124, 3-23, 2012.

Eberle, J. J., Fricke, H. C., Humphrey, J. D., Hackett, L., Newbrey, M. G., and Hutchison, J. H.: Seasonal variability in Arctic temperatures during early Eocene time, Earth Planet. Sc. Lett., 296, 481-486, 2010.

Edwards, E. J., Osborne, C. P., Strömberg, C. A. E., Smith, S. A., and Consortium, C. G.: The Origins of $\mathrm{C}_{4}$ Grasslands: Integrating Evolutionary and Ecosystem Science, Science, 328, 587591, 2010.

Francis, J. and Poole, I.: Cretaceous and early Tertiary climates of Antarctica: evidence from fossil wood, Palaeogeogr. Palaeocl., 182, 47-64, 2002.

Gough, D. O.: Solar interior structure and luminosity variations, Solar Phys., 74, 21-34, doi:10.1007/BF00151270, 1981.

Harrington, G. J., Eberle, J., Le-Page, B. A., Dawson, M., and Hutchison, J. H.: Arctic plant diversity in the Early Eocene greenhouse, P. Roy. Soc. B, 279, 1515-1521, 2012.

Heinemann, M., Jungclaus, J. H., and Marotzke, J.: Warm Paleocene/Eocene climate as simulated in ECHAM5/MPI-OM, Clim. Past, 5, 785-802, doi:10.5194/cp-5-785-2009, 2009.

Hollis, C. J., Taylor, K. W. R., Handley, L., Pancost, R. D., Huber, M., Creech, J. B., Hines, B. R., Crouch, E. M., Morgans, H. E. G., Crampton, J. S., Gibbs, S., Pearson, P. N., and Zachos, J. C.: Early Paleogene temperature history of the Southwest Pacific Ocean: Reconciling proxies and models, Earth Planet. Sc. Lett., 349-350, 53-66, 2012.

Huber, M.: A Hotter Greenhouse?, Science, 321, 353-354, 2008.

Huber, M. and Caballero, R.: The early Eocene equable climate problem revisited, Clim. Past, 7, 603-633, doi:10.5194/cp-7603-2011, 2011.

Hunter, S. J., Haywood, A. M., Valdes, P. J., Francis, J. E., and Pound, M. J.: Modelling equable climates of the Late Cretaceous: Can new boundary conditions resolve datamodel discrepancies?, Palaeogeogr. Palaeocl., 392, 41-51, doi:10.1016/j.palaeo.2013.08.009, 2013. 
Jaramillo, C., Ochoa, D., Contreras, L., Pagani, M., Carvajal-Ortiz, H., Pratt, L. M., Krishnan, S., Cardona, A., Romero, M., Quiroz, L., Rodriguez, G., Rueda, M. J., de la Parra, F., Morón, S., Green, W., Bayona, G., Montes, C., Quintero, O., Ramirez, R., Mora, G., Schouten, S., Bermudez, H., Navarrete, R., Parra, F., Alvarán, M., Osorno, J., Crowley, J. L., Valencia, V., and Vervoort, J.: Effects of Rapid Global Warming at the Paleocene-Eocene Boundary on Neotropical Vegetation, Science, 330, 957-961, 2010.

Kiehl, J. T. and Shields, C. A.: Sensitivity of the Palaeocene-Eocene Thermal Maximum climate to cloud properties, Philos. T. Roy. Soc. A, 371, 2001, doi:10.1098/rsta.2013.0093, 2013.

Kim, J.-H., van der Meer, J., Schouten, S., Helmke, P., Willmott, V., Sangiorgi, F., Koç, N., Hopmans, E. C., and Damsté, J. S. S.: New indices and calibrations derived from the distribution of crenarchaeal isoprenoid tetraether lipids: Implications for past sea surface temperature reconstructions, Geochim. Cosmochim. Acta, 74, 4639-4654, 2010.

Kump, L. R. and Pollard, D.: Amplification of cretaceous warmth by biological cloud feedbacks, Science, 320, 195, 2008.

Liu, Z., Notaro, M., Kutzbach, J., and Liu, N.: Assessing Global Vegetation-Climate Feedbacks from Observations, J. Climate, 19, 787-814, 2006.

Liu, Z., Wang, Y., Gallimore, R., Gasse, F., Johnson, T., deMenocal, P., Adkins, J., Notaro, M., Prenticer, I. C., Kutzbach, J., Jacob, R., Behling, P., Wang, L., and Ong, E.: Simulating the transient evolution and abrupt change of Northern Africa atmosphere-oceanterrestrial ecosystem in the Holocene, Quaternary Sci. Rev., 26, 1818-1837, 2007.

Liu, Z., Pagani, M., Zinniker, D., DeConto, R., Huber, M., Brinkhuis, H., Shah, S. R., Leckie, R. M., and Pearson, A.: Global cooling during the eocene-oligocene climate transition, Science, 323, 1187-1190, 2009.

Lohmann, G., Butzin, M., Micheels, A., Bickert, T., and Mosbrugger, V.: Effect of vegetation on the Late Miocene ocean circulation, Clim. Past Discuss., 2, 605-631, doi:10.5194/cpd-2-6052006, 2006.

Lowenstein, T. K. and Demicco, R. V.: Elevated Eocene atmospheric $\mathrm{CO}_{2}$ and its subsequent decline, Science, 313, 1928, 2006.

Lunt, D. J., Valdes, P., Dunkley Jones, T., Ridgwell, A., Haywood, A., Schmidt, D., Marsh, R., and Maslin, M.: $\mathrm{CO}_{2}$-driven ocean circulation changes as an amplifier of Paleocene-Eocene thermal maximum hydrate destabilization, Geology, 38, 875-878, 2010 a.

Lunt, D. J., Haywood, A. M., Schmidt, G. A., Salzmann, U., Valdes, P. J., and Dowsett, H. J.: Earth system sensitivity inferred from Pliocene modelling and data, Nat. Geosci., 3, 60-64, 2010b.

Lunt, D. J., Dunkley Jones, T., Heinemann, M., Huber, M., LeGrande, A., Winguth, A., Loptson, C., Marotzke, J., Roberts, C. D., Tindall, J., Valdes, P., and Winguth, C.: A modeldata comparison for a multi-model ensemble of early Eocene atmosphere-ocean simulations: EoMIP, Clim. Past, 8, 17171736, doi:10.5194/cp-8-1717-2012, 2012.

Markwick, P. and Valdes, P.: Palaeo-digital elevation models for use as boundary conditions in coupled ocean-atmosphere GCM experiments: a Maastrichtian (late Cretaceous) example, Palaeogeogr. Palaeocl., 213, 37-63, 2004.
Martin, P. A., Lea, D. W., Rosenthal, Y., Shackleton, N. J., Sarnthein, M., and Papenfuss, T.: Quaternary deep sea temperature histories derived from benthic foraminiferal $\mathrm{Mg} / \mathrm{Ca}$, Earth Planet. Sc. Lett., 198, 193-209, 2002.

Notaro, M., Wang, Y., Liu, Z., Gallimore, R., and Levis, S.: Combined statistical and dynamical assessment of simulated vegetation-rainfall interactions in North Africa during the midHolocene1, Global Change Biol., 14, 347-368, 2008.

Otto-Bliesner, B. and Upchurch, G.: Vegetation-induced warming of high-latitude regions during the late Cretaceous period, Nature, 385, 804-807, 1997.

Pagani, M., Caldeira, K., Berner, R., and Beerling, D. J.: The role of terrestrial plants in limiting atmospheric $\mathrm{CO}_{2}$ decline over the past 24 million years, Nature, 460, 85-88, 2009.

Pearson, P. N., van Dongen, B. E., Nicholas, C. J., Pancost, R. D., Schouten, S., Singano, J. M., and Wade, B. S.: Stable warm tropical climate through the Eocene Epoch, Geology, 35, 211-214, 2007.

Poulsen, C. J. and Zhou, J.: Sensitivity of Arctic Climate Variability to Mean State: Insights from the Cretaceous, J. Climate, 26, 7003-7022, doi:10.1175/JCLI-D-12-00825.1, 2013.

Pross, J., Contreras, L., Bijl, P. K., Greenwood, D. R., Bohaty, S. M., Schouten, S., Bendle, J. A., Rohl, U., Tauxe, L., Raine, J. I., Huck, C. E., van de Flierdt, T., Jamieson, S. S. R., Stickley, C. E., van de Schootbrugge, B., Escutia, C., and Brinkhuis, H.: Persistent near-tropical warmth on the Antarctic continent during the early Eocene epoch, Nature, 488, 73-77, 2012.

Roberts, C. D., LeGrande, A. N., and Tripati, A. K.: Climate sensitivity to Arctic seaway restriction during the early Paleogene, Earth Planet. Sc. Lett., 286, 576-585, 2009.

Sagoo, N., Valdes, P., Flecker, R., and Gregoire, L. J.: The Early Eocene equable climate problem: can perturbations of climate model parameters identify possible solutions?, Philos. T. Roy. Soc. A, 371, 2001, doi:10.1098/rsta.2013.0123, 2013.

Sewall, J. O., Sloan, L. C., Huber, M., and Wing, S.: Climate sensitivity to changes in land surface characteristics, Global Planet. Change, 26, 445-465, 2000.

Shellito, C. and Sloan, L.: Reconstructing a lost Eocene paradise: Part I. Simulating the change in global floral distribution at the initial Eocene thermal maximum, Global Planet. Change, 50, 117, doi:10.1016/j.gloplacha.2005.08.001, 2006a.

Shellito, C. and Sloan, L.: Reconstructing a lost Eocene Paradise, Part II: On the utility of dynamic global vegetation models in pre-Quaternary climate studies, Global Planet. Change, 50, 1832, doi:10.1016/j.gloplacha.2005.08.002, 2006b.

Shellito, C., Sloan, L., and Huber, M.: Climate model sensitivity to atmospheric $\mathrm{CO}_{2}$ levels in the Early-Middle Paleogene, Palaeogeogr. Palaeocl., 193, 113-123, doi:10.1016/S00310182(02)00718-6, 2003.

Shellito, C. J., Lamarque, J.-F., and Sloan, L. C.: Early Eocene Arctic climate sensitivity to $p \mathrm{CO}_{2}$ and basin geography, Geophys. Res. Lett., 36, L09707, doi:10.1029/2009GL037248, 2009.

Sloan, L. C. and Morrill, C.: Orbital forcing and Eocene continental temperatures, Palaeogeogr. Palaeocl., 144, 21-35, 1998.

Sloan, L. C. and Pollard, D.: Polar stratospheric clouds: A high latitude warming mechanism in an ancient greenhouse world, Geophys. Res. Lett., 25, 3517-3520, 1998. 
Sloan, L. C., Walker, J. C. G., and Moore Jr., T. C.: Possible Role of Oceanic Heat Transport in Early Eocene Climate, Paleoceanography, 10, 347-356, 1995.

Sluijs, A., Schouten, S., Pagani, M., Woltering, M., Brinkhuis, H., Damsté, J. S. S., Dickens, G. R., Huber, M., Reichart, G.-J., Stein, R., Matthiessen, J., Lourens, L. J., Pedentchouk, N., Backman, J., Moran, K., and the Expedition 302 Scientists: Subtropical Arctic Ocean temperatures during the Palaeocene/Eocene thermal maximum, Nature, 441, 610-613, 2006.

Sluijs, A., Röhl, U., Schouten, S., Brumsack, H.-J., Sangiorgi, F., Sinninghe Damsté, J. S., and Brinkhuis, H.: Arctic late Paleocene-early Eocene paleoenvironments with special emphasis on the Paleocene-Eocene thermal maximum (Lomonosov Ridge, Integrated Ocean Drilling Program Expedition 302), Paleoceanography, 23, PA1S11, doi:10.1029/2007PA001495, 2008.

Tindall, J., Flecker, R., Valdes, P., Schmidt, D. N., Markwick, P., and Harris, J.: Modelling the oxygen isotope distribution of ancient seawater using a coupled ocean-atmosphere GCM: Implications for reconstructing early Eocene climate, Earth Planet. Sc. Lett., 292, 265-273, 2010.

Utescher, T. and Mosbrugger, V.: Eocene vegetation patterns reconstructed from plant diversity - A global perspective, Palaeogeogr. Palaeocl., 247, 243-271, 2007.

Vicentini, A., Barber, J. C., Aliscioni, S. S., Giussani, L. M., and Kellogg, E. A.: The age of the grasses and clusters of origins of $\mathrm{C}_{4}$ photosynthesis, Global Change Biol., 14, 2963-2977, 2008.

Wang, Y., Notaro, M., Liu, Z., Gallimore, R., Levis, S., and Kutzbach, J. E.: Detecting vegetation-precipitation feedbacks in mid-Holocene North Africa from two climate models, Clim. Past, 4, 59-67, doi:10.5194/cp-4-59-2008, 2008.
Willis, K. and McElwain, J.: The Evolution of Plants, Oxford University Press, 2002.

Winguth, A., Shellito, C., Shields, C., and Winguth, C.: Climate Response at the Paleocene-Eocene Thermal Maximum to Greenhouse Gas Forcing - A Model Study with CCSM3, J. Climate, 23, 2562-2584, 2010.

Wolfe, A. P., Csank, A. Z., Reyes, A. V., McKellar, R. C., Tappert, R., and Muehlenbachs, K.: Pristine Early Eocene Wood Buried Deeply in Kimberlite from Northern Canada, PLOS ONE, 7, e45537, doi:10.1371/journal.pone.0045537, 2012.

Zachos, J. C., Pagani, M., Sloan, L., Thomas, E., and Billups, K.: Trends, Rhythms, and Aberrations in Global Climate $65 \mathrm{Ma}$ to Present, Science, 292, 686-693, 2001.

Zachos, J. C., Schouten, S., Bohaty, S., Quattlebaum, T., Sluijs, A., Brinkhuis, H., Gibbs, S. J., and Bralower, T. J.: Extreme warming of mid-latitude coastal ocean during the Paleocene-Eocene Thermal Maximum: Inferences from TEX86 and isotope data, Geology, 34, 737-740, 2006.

Zhou, J., Poulsen, C. J., Pollard, D., and White, T. S.: Simulation of modern and middle Cretaceous marine $\delta^{18} \mathrm{O}$ with an ocean-atmosphere general circulation model, Paleoceanography, 23, PA3223, doi:10.1029/2008PA001596, 2008.

Zhou, J., Poulsen, C. J., Rosenbloom, N., Shields, C., and Briegleb, B.: Vegetation-climate interactions in the warm mid-Cretaceous, Clim. Past, 8, 565-576, doi:10.5194/cp-8-565-2012, 2012. 